\title{
On entrainment rates in nocturnal marine stratocumulus
}

\author{
By BJORN STEVENS ${ }^{1,2 *}$, DONALD H. LENSCHOW ${ }^{2}$, IAN FALOONA ${ }^{2}$, C.-H. MOENG ${ }^{2}$, D. K. LILLY ${ }^{3}$, \\ B. BLOMQUIST ${ }^{4}$, G. VALI ${ }^{5}$, A. BANDY ${ }^{4}$, T. CAMPOS ${ }^{2}$, H. GERBER $^{6}$, S. HAIMOV $^{5}$, B. MORLEY ${ }^{2}$ \\ and D. THORNTON ${ }^{4}$ \\ ${ }^{1}$ Department of Atmospheric Sciences, University of California Los Angeles, USA \\ ${ }^{2}$ National Center for Atmospheric Research, Boulder CO, USA \\ ${ }^{3}$ School of Meteorology, University of Oklahoma, Norman OK, USA \\ ${ }^{4}$ Department of Chemistry, Drexel University, Philadelphia PA, USA \\ ${ }^{5}$ Department of Atmospheric Science, University of Wyoming, Laramie WY, USA \\ ${ }^{6}$ Gerber Scientific Inc., Reston, Virginia, USA
}

(Received 23 October 2002; revised 11 April 2003)

\section{SUMMARY}

The first research flight of the second Dynamics and Chemistry of Marine Stratocumulus field study is analysed. This case attracted our interest because it showed a consistently deepening cloud layer despite macroscopic conditions which previous work has suggested should be an indication of cloud thinning or breakup. Detailed analysis of the flight data shows that despite the cloud-top entrainment instability parameter being well beyond its critical value the cloud did indeed deepen through the night. Our best estimates show little indication of rapid changes in cloud top, while cloud base was found to be lowering at a rate of several metres per hour. This evolution, and independent measurements of trace-gas budgets, imply an entrainment rate of $0.0039 \pm 0.001 \mathrm{~m} \mathrm{~s}^{-1}$. This is compared to entrainment rates from recently proposed parametrizations (forced by the observed forcing of the cloud layer) which range from 0.002 to $0.008 \mathrm{~m} \mathrm{~s}^{-1}$. Two of the parametrizations we test reproduce the observed entrainment rates within their stated uncertainties, although subsequent tests show that one of these rules exhibits sensitivities to changes in the environmental conditions which are difficult to justify. Large-eddy simulation of the observed case was able to reproduce the macroscopic evolution of the layer, but in doing so had some difficulty in maintaining the observed mixing-line structure at cloud top. A comparison of the observed and simulated turbulent structure show these to be broadly consistent, although there is an indication that the structure of the simulated turbulence differs from the observations near the flow boundaries, particularly at cloud top.

KEYWORDS: Cloud-top entrainment instability Large-eddy simulation Turbulent mixing

\section{INTRODUCTION}

In commenting on attempts to relate the entrainment rate to the turbulent structure of the active fluid Phillips (1966) writes: 'It has, indeed, almost acquired the status of a hoary old chestnut'. Although the intervening decades have brought more and better experiments, new observations, and the advent of simulation, this view has tended towards confirmation. Indeed, accompanying the proliferation of new data one finds a steady march of new problems for which entrainment is a critical process. For instance, our inability to quantify (let alone understand) entrainment greatly hinders our ability to understand the dynamics of the stratocumulus-topped boundary layer (STBL); moreover, the inability of large-eddy simulation (LES) to resolve the processes at the entrainment interface undermines our confidence in its ability to accurately simulate entrainment (cf. Lilly 1968; Moeng et al. 1996; Bretherton et al. 1999; Stevens 2002).

New data, from a set of field observations collectively referred to as the second study of the Dynamics and Chemistry of Marine Stratocumulus (DYCOMS-II), were collected to address these issues (Stevens et al. 2003). DYCOMS-II took place during July 2001, in the heart of the north-east Pacific stratocumulus regime, approximately $500 \mathrm{~km}$ west-south-west of San Diego, California. Most of the DYCOMS-II flights,

* Corresponding author: Department of Atmospheric Sciences, University of California Los Angeles, 405 Hilgard Ave., Box 951565, Los Angeles, CA 90095-1565. e-mail: bstevens@atmos.ucla.edu

(C) Royal Meteorological Society, 2003. 


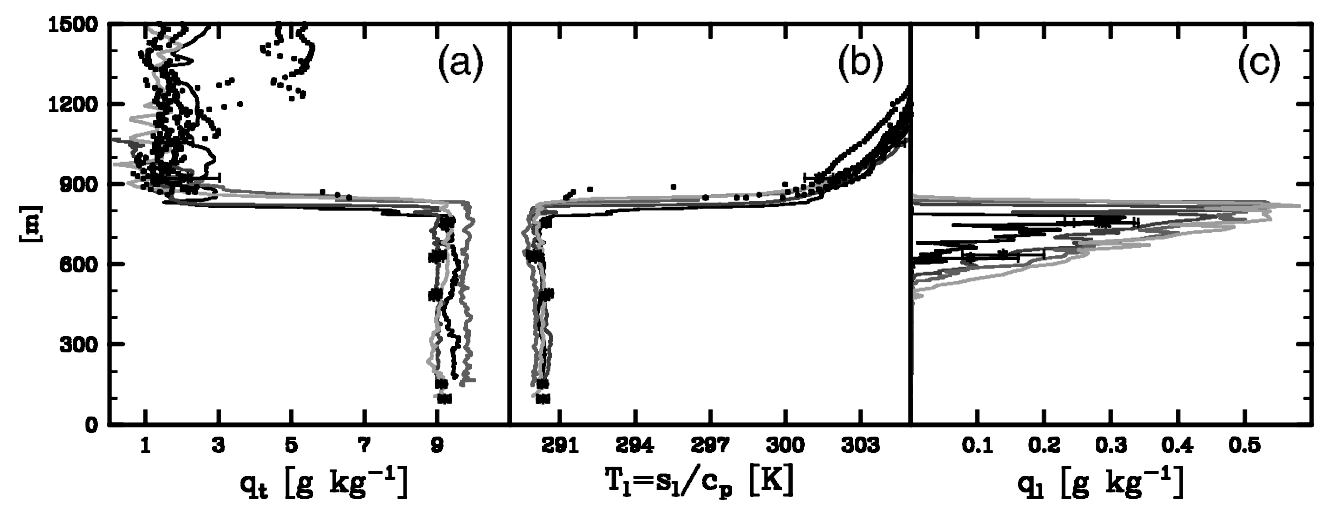

Figure 1. Cloud-layer state as observed during RF01: (a) total-water specific humidity $q_{t}$, (b) liquid-water static energy temperature $s_{1} / c_{p}$, and (c) liquid-water specific humidity $q_{1}$. Lines are from soundings, darker indicating earlier, filled circles and bars denote level-leg means and standard deviations, and dots denote dropsonde data from the above-cloud portion of the descent.

including the one analysed below, were nocturnal. Hence the absence of a temporally varying and difficult to quantify component of the energetics simplifies the analysis for these flights. The basic flight pattern during DYCOMS-II consisted of eleven 30-minute $(60 \mathrm{~km}$ diameter) circles, two each flown at four levels within the boundary layer, and three flown above the boundary layer. Interspersed among the circles were aircraft soundings and one circle (or segment of a circle) to probe the structure of the cloud-top interface. The length and quantity of circles allows one to reduce uncertainties in measurements of turbulent quantities due to sampling errors. In addition to a standard suite of instrumentation for measuring the turbulent state of the flow, special probes for fast response measurements of dimethyl sulfide (DMS) and ozone $\left(\mathrm{O}_{3}\right)$ were also deployed during DYCOMS-II. These trace gases have special properties which make them well suited as tracers of entrainment, and thus complement heat- and moisture-budget-based estimates of this important variable (Lenschow et al. 1999). Lastly, the remote-sensing capabilities of the aircraft, which included dropsondes, lidar, and millimetre cloud radar (Vali et al. 1998), greatly extended the effective sampling volume of the measurements, so that cloud evolution could be tracked throughout the flight.

Altogether DYCOMS-II consisted of nine research flights, six of which were nocturnal, and incorporated flight patterns well suited to the goals of this study. In this paper, however, we focus on only the first of these six flights, Research Flight 1 (RF01). Our attention was drawn to this case because the cloud layer showed clear evidence of significant thickening throughout the flight, despite macroscopic conditions which many believe should portend its desiccation.

These points are roughly illustrated in Fig. 1, where we show successive soundings made in the study area through the course of the flight, and mean measurements at specific heights from the $30 \mathrm{~min}$ level flight legs. Here the state of the layer is indicated by the total-water specific humidity $q_{\mathrm{t}}$, liquid-water specific humidity $q_{\mathrm{l}}$, and the liquidwater static-energy temperature

$$
T_{1} \equiv s_{1} / c_{p}=\left(T c_{p}+g z-L q_{1}\right) / c_{p}
$$

where $s_{1}$ is the liquid-water static energy, $g$ is the gravitational acceleration, $z$ is height above the surface as measured by the aircraft radar altimeter, $T$ is the ambient temperature, $L=2470 \mathrm{~kJ} \mathrm{~kg}^{-1}$ is the latent heat of vaporization, and $c_{p}=1015 \mathrm{~J} \mathrm{~kg}^{-1} \mathrm{~K}^{-1}$ is the isobaric specific heat of moist air. Both $q_{\mathrm{t}}$ and $s_{1}$ (alternatively $T_{1}$ ) are effectively 
adiabatic invariants of the moist system. Striking elements of this figure include: the extent to which the layer is well mixed; the stationarity of the free troposphere over the nearly eight hours between the first and last sounding; and the apparent thickening of the cloud with time.

The cloud layer is also unstable according to the theory of cloud-top entrainment instability (CTEI) developed by Randall (1980) and Deardorff (1980). This theory posits that whenever the buoyancy reversal parameter

$$
\kappa \equiv 1+\frac{\Delta s_{1}}{L \Delta q_{\mathrm{t}}}>\kappa_{*},
$$

mixtures of air from the free troposphere and from the cloud layer will be negatively buoyant, promoting enhanced mixing and the dissolution of the cloud. Essentially, $\kappa$ (which we define above in terms of $s_{1}$ and $q_{\mathrm{t}}$ ) measures the importance (from the perspective of buoyancy) of evaporative cooling versus warming for mixtures of cloudy and clear air. Thus $\kappa>\kappa_{*}$ says that the evaporative cooling is sufficient to make at least some mixtures of air negatively buoyant with respect to the cloud layer. For conditions encountered during DYCOMS-II, $\kappa_{*} \approx 0.23$. At a glance, $\Delta s_{1} \approx 10150 \mathrm{~J} \mathrm{~kg}^{-1}$, and $\Delta q_{\mathrm{t}} \approx$ $-7.5 \mathrm{~g} \mathrm{~kg}^{-1}$, which yields a value of $\kappa \approx 0.45$, which is significantly larger than $\kappa_{*}$.

Although past observations (e.g. as summarized by Kuo and Schubert (1988), and also see preliminary analysis of RF03 from DYCOMS-II by Gerber et al. (2002)) have provided little support for CTEI, recent modelling studies have been more ambiguous. Idealized three-dimensional studies (Lock and MacVean 1999) indicate that $\kappa>\kappa_{*}$ is a sufficient condition for energy to be produced by mixing at cloud top. In cloud layers whose state and forcing are more similar to that typically observed, simulations by Moeng (2000) find no evidence of an energetic contribution from CTEI. However, both Moeng (2000) and Lewellen and Lewellen (1998) find that in simulations with $\kappa>\kappa_{*}$, cloud fractions fall below unity and the cloud liquid-water path is precipitously reduced. Idealized two-dimensional simulations by M. K. MacVean (personal communication) suggest a more subtle relationship. They find that in the absence of other processes the cloud thinning time-scale is a decreasing function of $\kappa$ so that as $\kappa$ becomes significantly larger than $\kappa_{*}$ it becomes increasingly difficult for other processes to maintain the cloud layer. For the values of $\kappa$ observed during RF01, their analysis predicts a relatively rapid thinning time-scale (less than an hour), which at first glance seems difficult to reconcile with the apparent deepening of the layer.

This state of affairs motivates us to look a bit deeper into the RF01 data from DYCOMS-II, with the following questions in mind: Did the cloud layer really deepen this much? If so, is the buoyancy reversal parameter $\kappa$ as large as it seems? In either case, what were the entrainment rate and energetics of the layer during RF01 of DYCOMSII and how well are these captured by simple entrainment rate parametrizations and/or LES?

\section{BOUNDARY-LAYER STRUCTURE AND EVOLUTION}

In addressing questions such as those above, one typically thinks in terms of the Lagrangian evolution of a mixed layer within a uniform and stationary environment. Because it both simplifies the analysis, and helps focus the mind on what are thought to be the most essential issues, such a framework is the basis of most theoretical and numerical analysis. For instance, the assumption of the STBL being well mixed allows one to track the evolution of the STBL state by making measurements anywhere within the layer. By focusing on the Lagrangian evolution one can neglect the effects of 
(a)

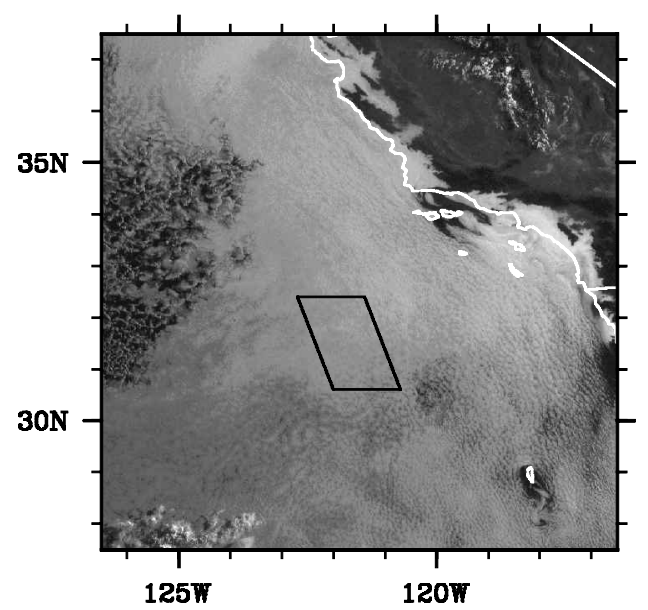

(b)

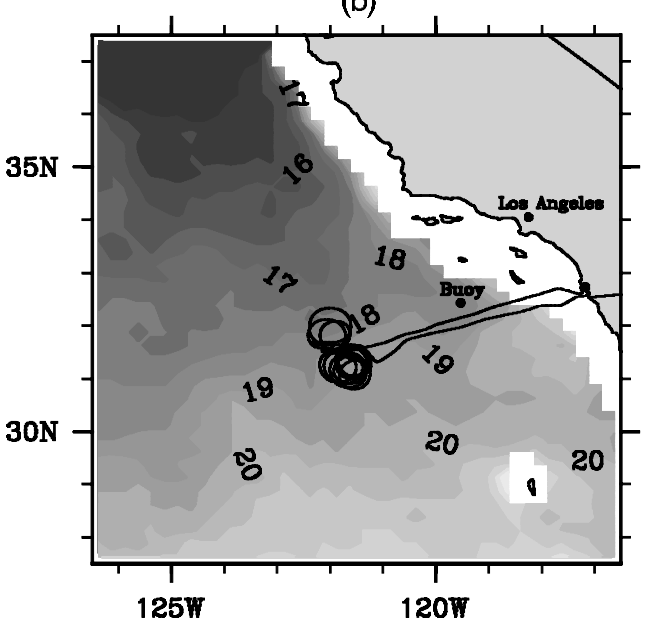

Figure 2. (a) GOES-10, Channel 1 Reflectance, from 1430 UTC (0730 h Pacific Daylight Time) 10 July 2001, with target area boxed. (b) Sea-surface temperatures $\left({ }^{\circ} \mathrm{C}\right)$ for $10 \mathrm{July}$, as derived from the Tropical Rainfall Measurement Mission Microwave Imager with the RF01 flight-track superposed. The numbers denote surface temperatures along contours (which are sometimes difficult to distinguish).

horizontal advection, and hence the problems associated with determining it; and to the extent to which environmental properties are slowly changing, or better yet constant, one can deduce these with a relatively small number of measurements-thereby facilitating the use of a single aircraft whose measurements are concentrated within the mixed layer. For these reasons it makes sense to evaluate the extent to which these conditions are met. We first focus on the question of the constancy of the environment; the extent to which the STBL measurements sample the Lagrangian evolution of a mixed layer are discussed thereafter.

\section{(a) Macroscopic environment}

From the point of view of the STBL, those aspects of the environmental state whose constancy one would most like to establish are: the heat and moisture fluxes at the surface, the radiative fluxes at the top of the layer, and the thermodynamic properties of the air overlying the layer. Given the uniformity in the cloud field as seen by satellite towards the end of the flight (Fig. 2(a)), one can at least entertain hope of a reasonably uniform large-scale environment.

The most important potential source of surface flux variability is a change in the sea surface temperature (SST) as the STBL advects downstream. Winds during RF01 were slightly over $7 \mathrm{~m} \mathrm{~s}^{-1}$ out of the west-north-west, which means that over an $8 \mathrm{~h}$ measurement interval the STBL would advect downstream approximately $200 \mathrm{~km}$. Fortunately there was no indication that SSTs varied substantially over the target area. Based on satellite imagery (e.g. Fig. 2) and an analysis of the radiometric surface temperatures measured by two probes mounted on the bottom of the aircraft fuselage, the SSTs varied by about $0.5 \mathrm{~K}$ over the bulk of the study area (as described later), with warmer water to the south-east. Although there is a tendency for the surface to warm with advection downstream, our later analysis of the temporal evolution of the STBL state shows that this warming is commensurate with the warming and moistening of the layer as it advects downstream. As a result downstream variations in surface fluxes can be expected to be within the uncertainty of our estimates of the mean. 
Even for a perfectly Lagrangian flight, wind shifts across the top of the STBL, and shear in the wind profile in the free troposphere can lead to situations whereby the air mass overlying the STBL at the end of the flight was 100 to $200 \mathrm{~km}$ away at the beginning of the flight. Changes in the state of the free troposphere can affect the radiative flux at the top of the STBL and the properties of the air being entrained. Despite clear wind shifts across the top of the STBL (with the free-tropospheric wind being more westerly), Fig. 1 indicates that the air immediately above the STBL remained remarkably constant in its thermodynamic properties. Among all of the DYCOMS-II flights, RF01 was perhaps the best behaved in this respect, which was one reason for selecting it for this study.

There is an elevated moist layer evident in two of the soundings in Fig. 1 (both from dropsondes during the last leg) which, although it shows little sign of directly interacting with the STBL, might be expected to modify the radiative forcing at the top of the layer. It turns out that this layer was evident in almost all of the soundings, albeit at heights above $1500 \mathrm{~m}$ and hence not apparent in Fig. 1. The one exception was along the northernmost portion of the first flight leg, which appeared to be under drier air throughout the troposphere. This apparent north-south gradient in upper-level precipitable water is consistent with Tropical Rainfall Measurement Mission Microwave Imager (TMI) retrievals (not shown). Nonetheless, all lines of evidence suggest that for the data we analyse later (which tended to be to the south of those initial soundings), an elevated moist layer containing 3-5 mm of precipitable water was always present. Calculations with the $\mathrm{Fu}$ and Liou (1993) $\delta$-four stream radiative-transfer code using the observed state, but with moist layers similar to those observed inserted at altitudes ranging from 1200-2200 $\mathrm{m}$, indicate that while the moist layer significantly affects the radiative forcing at the top of the cloud layer, the exact altitude of this layer has a relatively small effect (i.e. $\pm 10 \%$ ). Thus we conclude that, at least from the perspective of the upper boundary, conditions were also relatively constant throughout the flight.

\section{(b) Lagrangian analysis}

Given the apparent homogeneity in the upper and lower boundaries of the STBL, conditions during RF01 would appear ideal for Lagrangian flight manoeuvres. However, Fig. 2 shows that this goal was not always realized. If it had been, we would have seen the locus of centre points from the different circles tracing a trajectory from the westnorth-west following the mean wind. This roughly holds for the first three circles, but a navigation error as we started the fourth circle led us to fly the remaining circles approximately $60 \mathrm{~km}$ downstream of the target air mass. Some of this was mitigated in the last four circles, whereby to stay out of a military warning area the aircraft backtracked slightly to the north-west.

To illustrate the effects of these excursions in Fig. 3 we plot $\mathbf{x}_{0}$, the position of the STBL air column sampled during each flight circle, according to where we estimate it to have been at some common time $t_{0}=9300 \mathrm{~s}$ after take-off. This time was chosen to equal the midpoint time of the first boundary-layer flight circle. If we had been flying a perfectly Lagrangian track we would expect all of the flight circles to overlay one another identically. To make this figure we estimate the mean vector wind $\mathbf{U}$ and its time variation $\partial \mathbf{U} / \partial t$ from all the circles flown in the STBL, and then adjust the vector position of the air mass $\mathbf{x}$ at some time $t$ to its estimated position $\mathbf{x}_{0}$ at time $t=t_{0}$, according to

$$
\mathbf{x}_{0}=\mathbf{x}-\mathbf{U}\left(t-t_{0}\right)-\frac{1}{2} \frac{\partial \mathbf{U}}{\partial t}\left(t-t_{0}\right)^{2}
$$



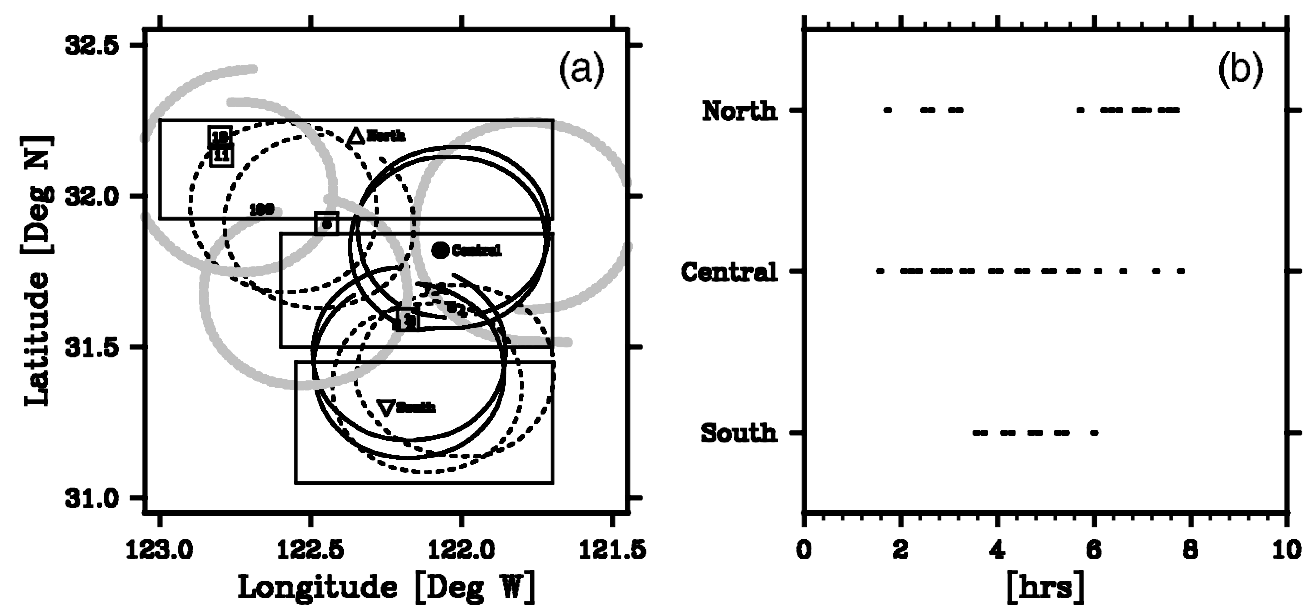

Figure 3. (a) Estimated position of STBL air masses (as sampled along circular flight-paths) at $t=t_{0}$. Solid black circles denote cloud circles, dashed black circles denote circles in sub-cloud layer. Thickened grey circles denote flight circles above the STBL. Order and position of aircraft soundings are denoted by numbers. (Note that soundings 1, 2 and 3 are very near each other in the centre of the plot, and soundings 9 and 10 also are adjacent to one another.) The boxed numbers $(1,8,11,12)$ indicate the four soundings which extended through the depth of the STBL and are plotted in Fig. 1. The large boxes denote three study regions: central, north and south. (b) Short blackened intervals indicate the time spent in one of three study regions.

This method is not perfect: turbulent fluctuations in the wind lead to diffusion of the air mass, and estimates of $\partial \mathbf{U} / \partial t$ are compromised by spatial variability in the observed wind. Nonetheless, it gives a reasonable idea of how the air mass is sampled.

This analysis suggests that by separately considering the evolution of three regions (north, south and central) some of the effects of deviating from a Lagrangian flight plan can be mitigated. Because the central region is best sampled in both space and time, we focus our attention there. Although the subsequent analysis is based on this three-region breakdown we also considered other breakdowns, for instance, a five-region breakdown with a smaller central region. This analysis did not yield important new information; i.e. it did not produce systematic east-west variability, and it had fewer data in each region.

By segregating data according to whether they fell in the north, south, central, or none of the regions, and assuming that the layer is well mixed in terms of adiabatically invariant quantities (so we can treat measurements at all heights equivalently), we can evaluate the Lagrangian evolution of important state variables in the STBL (technical details of this and subsequent analysis of the aircraft data are discussed in appendix A; our methods for estimating uncertainty are discussed in appendix B). This is shown in Fig. 4 for $s_{1}$ and $q_{\mathrm{t}}$. The data suggest $1.7 \pm 0.26 \mathrm{~g} \mathrm{~kg}^{-1} \mathrm{~d}^{-1}$ of moistening and about $1.9 \pm 0.3 \mathrm{~K} \mathrm{~d}^{-1}$ of warming of the STBL as it advects downstream over warmer water. These are not too different from what one would expect if the air-sea temperature and moisture differences remained fixed (cf. Fig. 2).

Segregating data by Lagrangian region also allows us to separate spatial and temporal derivatives, with the former being indicated by systematic differences among the study regions. Although the data indicate clear temporal trends in $q_{\mathrm{t}}$ and $s_{\mathrm{l}}$, only $s_{\mathrm{l}}$ shows obvious spatial gradients, with cooler air to the north. These gradients tend to be somewhat larger than what we would expect based on the Lagrangian changes of $s_{1}$ estimated above. The lack of a discernible spatial gradient in $q_{\mathrm{t}}$ may reflect its longer 

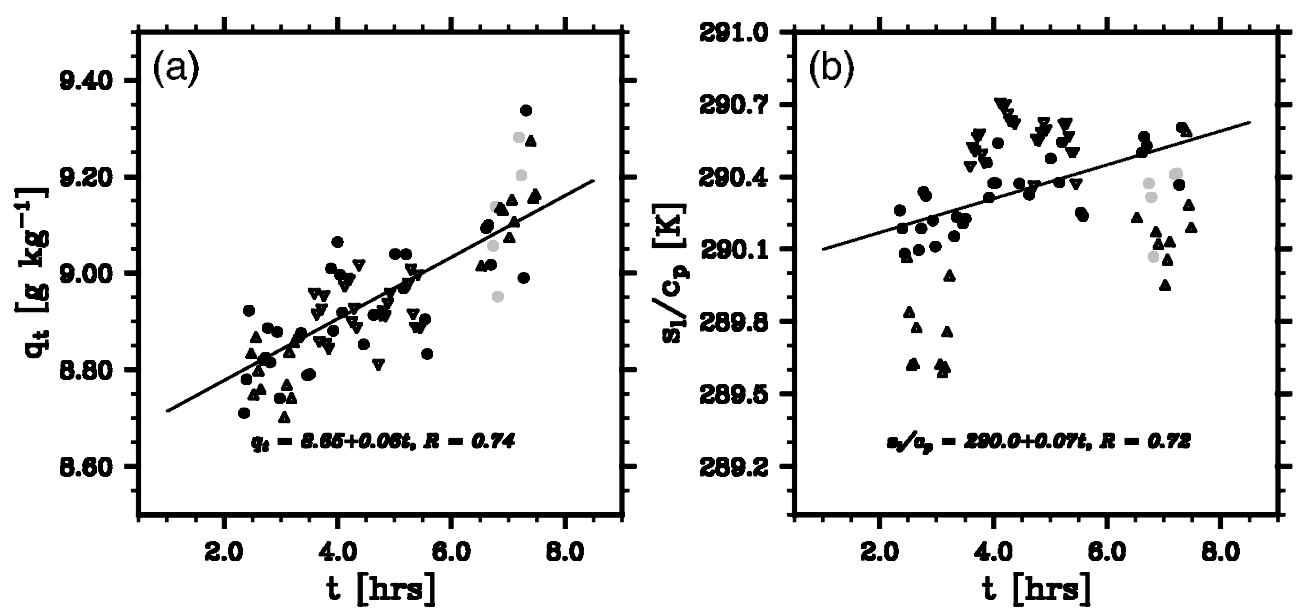

Figure 4. Estimated temporal variation of (a) $q_{\mathrm{t}}$ and (b) $T_{1}$ in the STBL (see text) derived from 2.5 min averages of state variables measured along boundary-layer legs during RF01. Note that the regression lines only fit the data (solid circles) taken in the central region. Data taken in the northern and southern regions are denoted by upperand lower-pointing triangles, respectively. Data which did not fall in a study region are denoted by grey circles.

adjustment time-scale as predicted by mixed-layer theory*, or the obscuration of a signal by larger mesoscale variations.

At temperatures and pressures characteristic of the middle of the STBL, $\mathrm{d} q_{\mathrm{s}} / \mathrm{d} T \approx$ $0.7 \mathrm{~g} \mathrm{~kg}^{-1} \mathrm{~K}^{-1}$. This implies that, if the time rate of change of $T_{1}$ (in units of $\mathrm{K} \mathrm{d}^{-1}$ ) and $q_{\mathrm{t}}$ (in units of $\mathrm{g} \mathrm{kg}^{-1} \mathrm{~d}^{-1}$ ) have the same magnitude, then $\mathrm{d} q_{\mathrm{s}} / \mathrm{d} t$ (which is just $\left.\left(\mathrm{d} q_{\mathrm{s}} / \mathrm{d} T\right)\left(\mathrm{d} T_{1} / \mathrm{d} t\right)\right)$ will be less than $\mathrm{d} q_{\mathrm{t}} / \mathrm{d} t$; hence from a saturation point of view moistening the STBL dominates over warming and we expect the change in the mean state to be accompanied by a slight lowering of cloud base with time. This is indeed evident in Fig. 5 where the lifting condensation level (LCL) is plotted along with cloud base as determined from aircraft soundings. The gradual lowering of cloud base predicted by changes in the LCL is also evident in the sounding data. The consistency between LCL estimates of cloud base and the measured cloud base from aircraft penetrations also supports the mixed-layer assumption made in our initial analysis. The data also show a consistently lower cloud base to the north, consistent with the spatial variations in $s_{1}$ discussed previously. Because the latter soundings, plotted in Fig. 1, tended to preferentially be in the northern study area, the profile data exaggerate the lowering of cloud base. Nonetheless, to the extent that these data indicate a trend they indicate that cloud base is lowering. Although this finding is counter to the idea that $\kappa>\kappa_{*}$ portends cloud break-up, it is less difficult to reconcile with the idea that the cloud deepens simply because other processes are sufficiently strong to dominate the tendency of buoyancy reversal processes to thin the cloud (e.g. M. K. MacVean, personal communication).

The evolution of cloud top during the course of the flight is much more difficult to assess. Unlike cloud base, for which we had measurements (or proxies) for nearly the entire flight, continuous estimates of cloud top only occurred over three intervals, and these tended to measure cloud depth in different Lagrangian regions. If variability in the

\footnotetext{
* Schubert et al. (1979) show that the adjustment time of moist static energy $\boldsymbol{h}=\boldsymbol{s}_{\mathrm{l}}-\boldsymbol{L} q_{\mathrm{t}}$, and $q_{\mathrm{t}}$ are commensurate. However, because $h$ depends linearly on $q_{\mathrm{t}}$, their analysis does not clearly separate temperature and moisture. Repeating it in terms of $s_{1}$ and $q_{\mathrm{t}}$ shows the latter to have a longer adjustment time.
} 

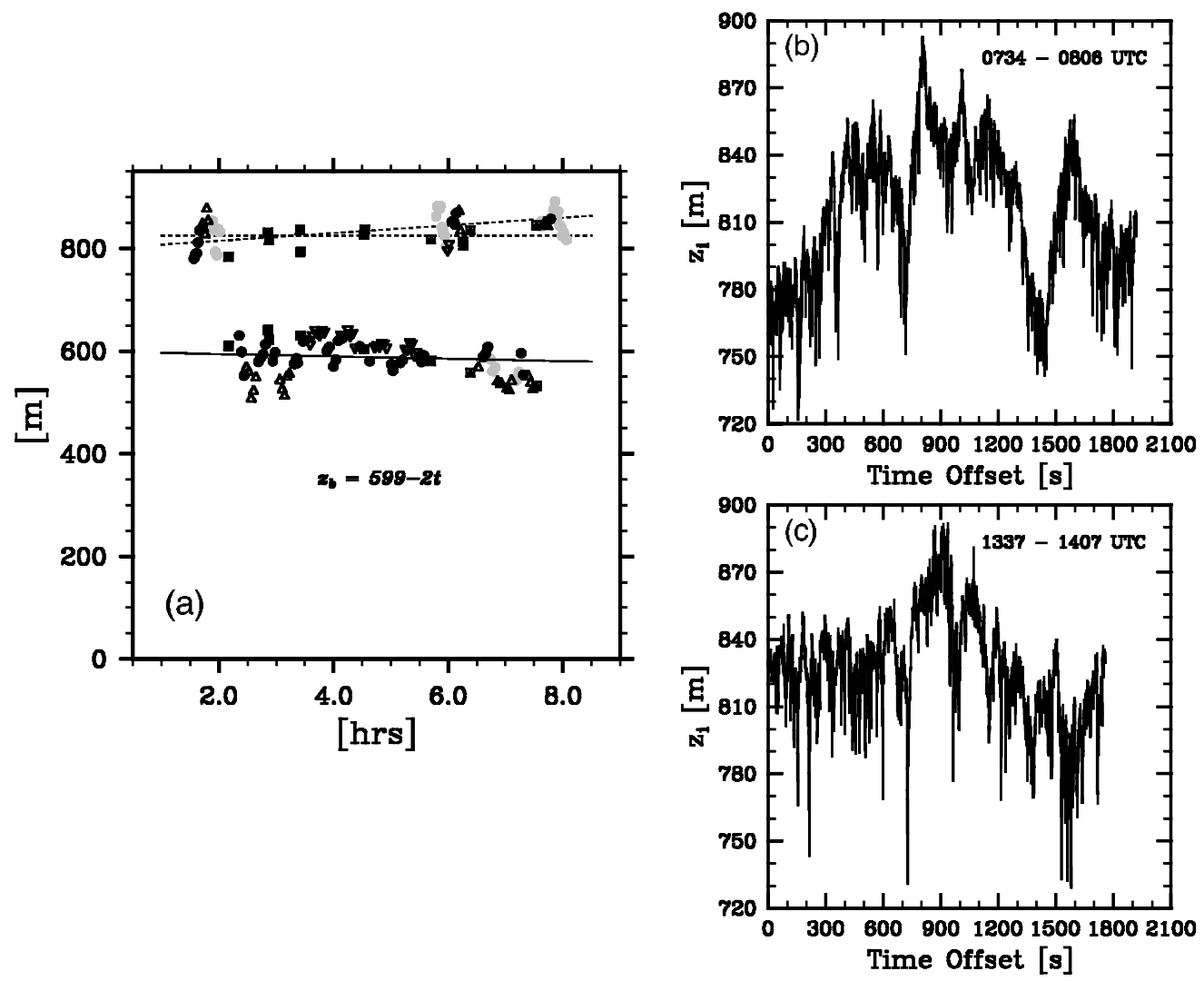

Figure 5. Estimated temporal variation of cloud-boundaries. Level-leg data are used to calculate lifting condensation level which is plotted following the symbol convention of Fig. 4, sounding data are indicated with open squares, filled with a region indicator symbol. Cloud top is estimated from soundings and radar/lidar retrievals. The radar and lidar retrievals are averages over sub-intervals and identified by study region. (b)-(c) Examples of the $1 \mathrm{~s}$ lidar estimates of cloud top, from the first and last lidar leg, respectively. (a) The regression on points in the central study region is used to estimate the evolution of cloud base, and two lines are drawn by eye to indicate the plausible evolution of cloud top. One corresponds to no change in time, the other to a value of $\mathrm{d} z_{i} / \mathrm{d} t$ of $7.5 \mathrm{~m} \mathrm{~h}^{-1}\left(2.1 \mathrm{~mm} \mathrm{~s}^{-1}\right)$. See text for further explanation.

cloud top was confined to small spatial scales (of the order of kilometres) this might not be a problem. However, in addition to illustrating the uniformity of cloud coverage the lidar returns in Figs. 5(b) and (c) indicate considerable mesoscale variability in cloud height. Moreover, spatial coherence in these patterns is not readily discernible and thus difficult to correct for. This degree of variability, and the failure of the cloudtop measurements to sample the same air mass, make it difficult to put meaningful bounds on the change in cloud-top height through the course of the flight. For this reason no attempt was made to fit lines to the cloud-top height data, and instead fits were drawn by eye as a means of evaluating the plausibility of varying scenarios. Fortunately, our inability to be more quantitative in this respect does not undermine our ability to constrain the thermodynamic budgets.

Thus, while the cloud boundary data suggest that the cloud layer is probably deepening as it advects downstream, it remains to be seen if the layer truly satisfies the CTEI criterion as set forth by Randall (1980) and Deardorff (1980). To address this question Fig. 6 shows the data from all cloud-top penetrations plotted in $q_{\mathrm{t}}, T_{1}$ space. 


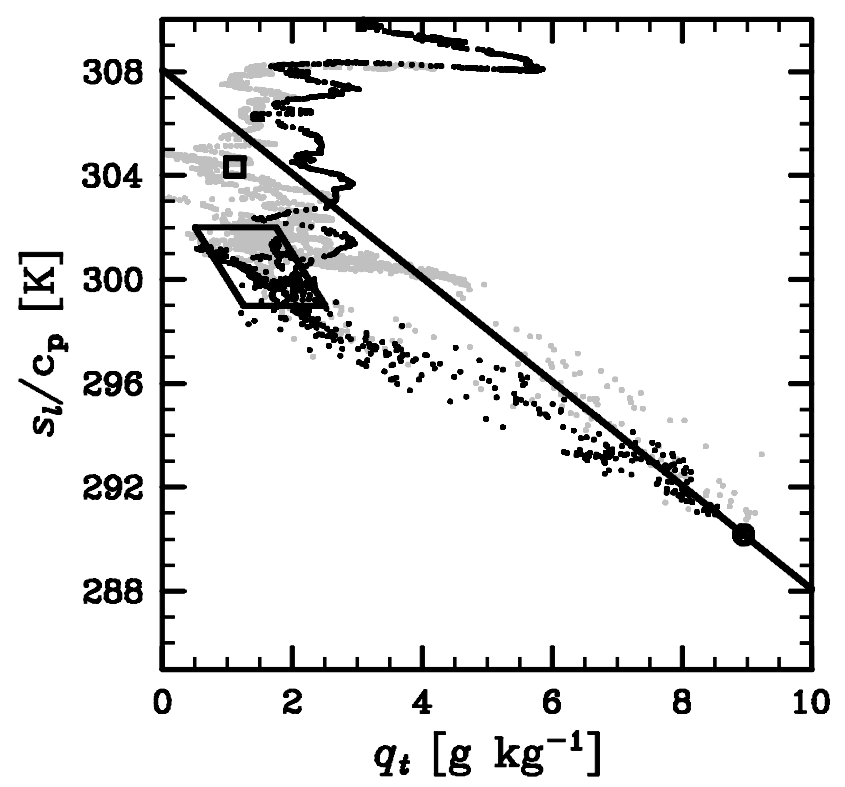

Figure 6. $2.5 \mathrm{~Hz}$ data (i.e. fast $25 \mathrm{~Hz}$ data sub-sampled every fifth point) showing $\left(q_{\mathrm{t}}, T_{1}\right)$ from all cloud penetrations during RF01. Black symbols indicate that sample is drawn from the central region, other symbols indicate data from cloud penetrations elsewhere. The circle marker lower right shows best estimate of STBL state from Fig. 4, the rhomboid shows estimated properties of free-tropospheric air which is ultimately mixing with air from the STBL, and the small square (near $304 \mathrm{~K}$ ) shows properties of free troposphere as deduced from a level-leg flow near $1050 \mathrm{~m}$. Free-tropospheric states to the left of the solid line denote layers whose value of $\kappa$ are greater than $\kappa_{* \text { I }}$ and hence unstable according to the classical formulation of CTEI. See text for further explanation.

It shows that, at least within the central study region, the data lie on a mixing line well on the unstable side of the neutrally stable mixing line. Along one of the cloud penetrations which occurred outside the central study region there is evidence that the aforementioned elevated moist layer actually intersected the cloud layer, leading to a region whose mixing line was slightly stable with respect to CTEI. However, this appears to be an isolated case, as other soundings outside the central study region lie on the same mixing line as the data within the central region. Thus we conclude that for the most part the boundary-layer air, whose evolution we analyse, was mixing with air in the free troposphere whose mixing ratio was about $1.5 \mathrm{~g} \mathrm{~kg}^{-1}$ and whose effective temperature $\left(T_{1}\right)$ was $300-301 \mathrm{~K}$. This implies $\Delta q_{\mathrm{t}}=7.5 \pm 0.5 \mathrm{~g} \mathrm{~kg}^{-1}$ and $\Delta T_{1}=10 \pm 1 \mathrm{~K}$-values commensurate to what one would have estimated from Fig. 1 and unequivocal in their satisfaction of the CTEI criterion.

In summary, this more careful analysis of the RF01 data does support the idea that the cloud layer was indeed unstable with respect to CTEI, yet still thickened-both through a lowering of cloud base and a rising of cloud top.

\section{ENTRAINMENT-RATE ESTIMATES}

If one defines entrainment as the mixing of air from the quiescent free troposphere into the STBL, one can quantify its rate (a velocity) in a variety of ways. To do this, consider the general equation for the expected value of a scalar (denoted by an overbar, 
with primes denoting deviations therefrom) in a turbulent flow

$$
\frac{\partial \bar{\phi}}{\partial t}+\bar{w} \frac{\partial \bar{\phi}}{\partial z}=-\frac{\partial}{\partial z}\left(\psi_{\phi}+F_{\phi}\right)+S_{\phi},
$$

where $\psi_{\phi} \equiv \overline{w^{\prime} \phi^{\prime}}$ is the turbulent flux, $F_{\phi}$ is the vertical component of some flux (which acts on the scalar through its gradient, e.g. radiation or precipitation when $\phi=s_{1}$, ) and $S$ is some generalized source term, e.g. for reacting gases. By integrating (3) from a height $z_{i-} \equiv z_{i}-\epsilon$, just below the top of the layer, to a height $z_{i+} \equiv z_{i}+\epsilon$, just above the top of the layer, it is straightforward (cf. Lilly 1968; Stevens 2002) to show that if $\epsilon$ is sufficiently small compared to $z_{i}$

$$
\left(\frac{\mathrm{d} z_{i}}{\mathrm{~d} t}-\bar{w}\left(z_{i}\right)\right) \Delta \bar{\phi}=-\psi_{\phi}\left(z_{i-}\right)+\Delta F_{\phi} .
$$

Here $z_{i}$ denotes the base of the temperature inversion, equivalently the top of the cloud layer, $\epsilon$ can be thought of as being of the order of the undulation depth of cloud top, and $\Delta$ denotes a difference in a quantity measured at $z_{i+}$ and $z_{i-}$, respectively; $\epsilon$ can be estimated from the lidar data in Fig. 5 . For $5 \mathrm{~km}$ subsegments, $z_{i}$ has a standard deviation of $13 \mathrm{~m}$ which roughly doubles as the subsegment length increases to $50 \mathrm{~km}$. In both cases this is much less than the mean depth of the layer, so the small $\epsilon$ assumption implicit above is warranted. In (4) $\mathrm{d} z_{i} / \mathrm{d} t-\bar{w}$ denotes the diabatic growth rate of the layer, i.e. the entrainment velocity $E$, which is necessary to close a bulk formulation of the mixed layer.

This discussion leads to two methods for estimating $E$. One, which we call the ratio method, estimates $E$ as

$$
E=\frac{-\psi_{\phi}\left(z_{i-}\right)+\Delta F_{\phi}}{\Delta \bar{\phi}}
$$

the other, which we call the difference method, estimates $E$ kinematically as

$$
E=\frac{\mathrm{d} z i}{\mathrm{~d} t}-\bar{w} .
$$

Because the mean subsidence velocity valid at cloud top, i.e. $\bar{w}\left(z_{i}\right)$, is difficult to measure, we focus on the ratio method for now. An advantage of this method is that it holds for every scalar that satisfies (3). Moreover, for scalars whose greatest source of uncertainty is the kinematic flux at $z_{i}$, multiple estimates of $E$ can be obtained by estimating the flux using independent means. For instance, given $F_{\phi}, \psi_{\phi}\left(z_{i-}\right)$ can be estimated either by eddy correlation or from a budget residual (cf. Russell et al. 1999). For the latter we obtain

$$
\psi_{\phi}\left(z_{i-}\right)=-z_{i} \frac{\mathrm{d} \bar{\phi}}{\mathrm{d} t}+\psi_{\phi}(0)-\left(F_{\phi}\left(z_{i-}\right)-F_{\phi}(0)\right)+\int_{0}^{z_{i-}} S_{\phi} \mathrm{d} z
$$

which requires estimates of $\mathrm{d} \bar{\phi} / \mathrm{d} t$, as well as contributions to $\phi$ from source and surface fluxes. In some cases each of these terms can be estimated using slow-response instruments. In contrast, eddy-correlation-based estimates of $\psi_{\phi}\left(z_{i-}\right)$ always require fast sampling capability. Moreover, the flux needs to be estimated directly at the entrainment interface. In practice the need to sample directly at $z_{i}$ - can be avoided by estimating $\psi_{\phi}$ at multiple levels throughout the STBL (including near the surface), and then using the fact that in quasi-steady state $\psi_{\phi}+F_{\phi}$ must be linear* through the

* Strictly speaking this is only true if $\partial S_{\phi} / \partial z$ is negligible, which is thought to be the case for the scalars we consider. 


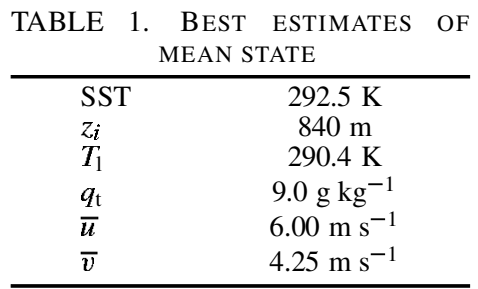

See text for explanation.

layer, to extrapolate the profiles to $z_{i-}$. As discussed by Stevens et al. (2003), the flight plans during DYCOMS-II, and the package of airborne instrumentation, were designed specifically around these objectives, thus allowing for optimal estimates of $E$.

With these points in mind we first examine the heat and moisture budgets, which are strongly constrained by the previous analysis of cloud base, to estimate $E$ using (5) and (7). Due to the absence of both sunlight and appreciable drizzle during RF01, the only diabatic term which must be considered is that due to the flux of radiant energy at long wavelengths, $F_{\mathrm{lw}}(z)$.

For the surface fluxes, eddy-correlation estimates extrapolated to the surface yield sensible- and latent-heat fluxes of $7 \pm 10$ and $115 \pm 14 \mathrm{~W} \mathrm{~m}^{-2}$, respectively. The large uncertainty in the sensible-heat fluxes arises because we need to extrapolate the sum of the radiative and kinematic heat fluxes to the surface, and both the radiative and kinematic fluxes have large uncertainties in the cloud layer*. If we instead calculate the surface sensible-heat fluxes by extrapolating only the below-cloud measurements to the surface we arrive at a similar mean estimate which has considerably reduced uncertainty, but which is valid for a more limited time window.

We have also estimated the surface fluxes using the TOGA-COARE $\dagger$ bulk flux algorithm (Fairall et al. 1996, version 2.5b). As input to this algorithm we assumed that the mean state over the central study region, derived from Fig. 4 and tabulated in Table 1, was valid at a height of $50 \mathrm{~m}$. The SST used in this was taken from a composite of radiometric surface temperatures estimated during flight periods (both soundings and level legs) in the sub-cloud layer. These measurements yield values systematically $0.5 \mathrm{~K}$ warmer than the satellite estimates, which is in the range of uncertainty of the two methods. Based on this input the algorithm predicts surface sensible-heat fluxes of $17 \pm 3 \mathrm{~W} \mathrm{~m}^{-2}$ and latent-heat fluxes of $115 \pm 15 \mathrm{~W} \mathrm{~m}^{-2}$, which are reasonably consistent with the direct estimates.

To estimate the radiative forcing, which enters into the budget of $s_{1}$, we used a radiative-transfer model forced by the observed state of the atmosphere. In principle measurements could be used, but using the models allows us to better evaluate the detailed vertical structure of the profile. The degree to which the model introduces possible errors can moreover be checked by comparing the measurements to the model at levels where we have data. In these calculations the mean STBL state and the surface temperatures were given the values in Table 1 . These implied a cloud base of $600 \mathrm{~m}$ and a cloud-top liquid-water content of $0.47 \mathrm{~g} \mathrm{~kg}^{-1}$. Above regions for which we had in situ data (typically above $3 \mathrm{~km}$ depending on sounding level) we used the radiosonde sounding taken at San Diego on 00 UTC 10 July blended to the McClatchey midlatitude summer atmosphere between 10 and $15 \mathrm{~km}$. Above the STBL we evaluated

* For the radiative fluxes we use fluxes calculated from a radiative-transfer code (see later) and estimate the uncertainty as the change in the radiative flux over a $50 \mathrm{~m}$ interval centred at the measurement height.

† Tropical Ocean and Global Atmosphere, Coupled Ocean-Atmosphere Response Experiment. 


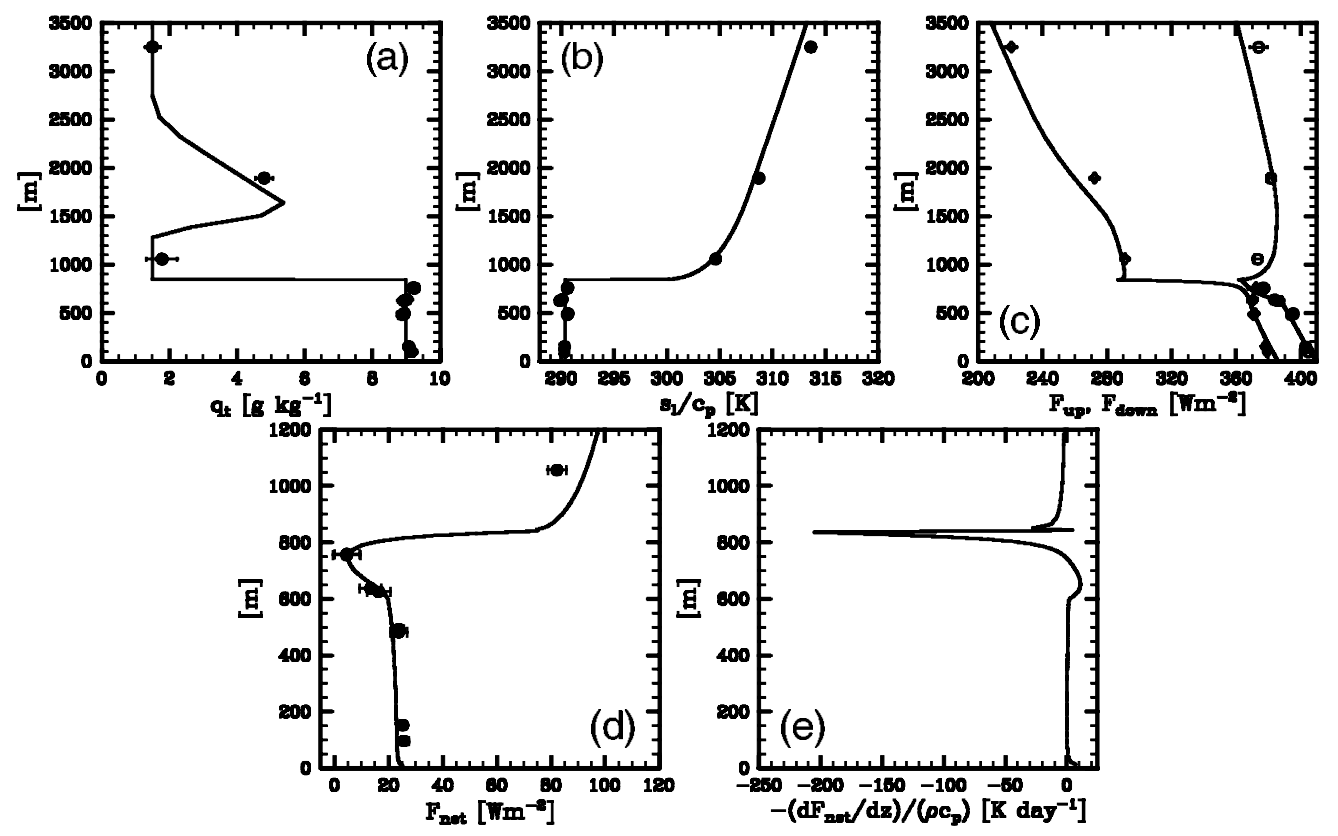

Figure 7. Idealized soundings used to drive radiative calculations, and resulting radiative fields: (a) $q_{\mathrm{t}}$, (b) $s_{\mathrm{l}}$, (c) $F_{\mathrm{lw}}^{\vee}$ and $F_{\text {lw }}^{\uparrow}$ from calculations (lines) and measured (diamonds and circles, respectively), (d) net flux, and (e) heating rate. Note the different vertical scale on the lower plots. See text for explanation of symbols.

radiative fluxes for mean state profiles as provided by all of the soundings. Because the free-tropospheric temperature varied little among the measurements, the radiative calculations were not sensitive to which profile we used. Thus to simplify matters we fit the synthetic profile

$$
T_{1}= \begin{cases}297.5+\left(z-z_{i}\right)^{1 / 3}, & z_{i}<z<z_{*}, \\ 297.5+\gamma\left(z-z_{*}\right), & z_{*}<z\end{cases}
$$

where $\gamma=3.5 \mathrm{~K} \mathrm{~km}^{-1}$ and $z_{*}=z_{i}+(3 \gamma)^{-3 / 2} \approx 1770 \mathrm{~m}$ is chosen to match lapse rates at $z_{*}$. For the moisture profile above $z_{i}$ we specified a background profile of $q_{\mathrm{t}}=1.5 \mathrm{~g} \mathrm{~kg}^{-1}$ with an additional moist layer whose magnitude of

$$
1.5+4.0\left(1-\frac{z-1200}{1000}\right) \mathrm{g} \mathrm{kg}^{-1} \text { for } 1200 \mathrm{~m}<z \leqslant 2200 \mathrm{~m}
$$

was smoothed with a 1-2-1 filter in the vertical (where the grid spacing in the calculation was $8.4 \mathrm{~m}$ in the mixed layer and approximately $200 \mathrm{~m}$ in the vicinity of the moist layer) before being added to the background value. Although not shown, the fit for $T_{1}$ agreed remarkably with the sounding data, and the fit for moisture captured the essence of the elevated moist layer, e.g. Fig. 7.

Results of radiative calculations based on this profile are also illustrated in Fig. 7. The measured and calculated profiles of radiative fluxes agree quite well, with the major point of disagreement being the downwelling component along the cloud-top leg, and perhaps the upwelling component just above cloud top. From the perspective of a mixed-layer model (and the heat-budget estimates of entrainment), the most important quantity is the radiative-flux divergence across the STBL, i.e. $F_{\mathrm{lw}_{\mathrm{w}}}\left(z_{i+}\right)-F_{\mathrm{lw}}(0)$. It is 
approximately $50 \pm 5 \mathrm{~W} \mathrm{~m}^{-2}$. Note that from Fig. 7(d) the radiative-flux jump across cloud top is $\approx 70 \mathrm{~W} \mathrm{~m}^{-2}$, which is compensated for by warming associated with $\approx 20 \mathrm{~W} \mathrm{~m}^{-2}$ of flux convergence concentrated near cloud base.

Based on these estimates of the diabatic and surface fluxes, and previous estimates of other terms (and their uncertainties) entering into the budget-based equations for $E$, we can estimate $E$, and its uncertainty, from the moisture budget as

$$
E=\frac{z_{i}\left(\mathrm{~d} q_{\mathrm{t}} / \mathrm{d} t\right)-\psi_{q_{\mathrm{t}}}(0)}{\Delta q_{\mathrm{t}}}=0.344 \pm 0.11 \mathrm{~cm} \mathrm{~s}^{-1} \text {. }
$$

From the heat budget we estimate

$$
E=\frac{z_{i}\left(\mathrm{~d} s_{1} / \mathrm{d} t\right)-\psi_{s_{1}}(0)+\left(F_{1 \mathrm{w}}\left(z_{i+}\right)-F_{1 \mathrm{w}}(0)\right)}{\Delta s_{1}}=0.46 \pm 0.08 \mathrm{~cm} \mathrm{~s}^{-1} .
$$

Techniques for estimating the uncertainties (which here are limited to random sampling, rather than systematic errors) in various quantities are discussed in appendix B. In this case, the uncertainty in $E$, denoted $\sigma_{E}$, is predominantly due to uncertainties in estimates of the surface (and, in the case of $s_{1}$, radiative) fluxes. Uncertainties associated with the jumps and the time rate-of-change terms are smaller but still significant.

The potential for large uncertainties in any individual estimate of $E$ was a primary motivation for DYCOMS-II, where the strategy was to obtain multiple independent estimates to help us bound our uncertainty, as well as give us some indication of possible systematic errors. Towards this end we have also estimated the entrainment rate using direct estimates of the turbulent fluxes at the top of the STBL for $q_{\mathrm{t}}, \mathrm{DMS}$ and $\mathrm{O}_{3}$. Of these both $q_{\mathrm{t}}$ and $\mathrm{O}_{3}$ have been used as tracers of entrainment before, e.g. during DYCOMS-I (Kawa and Pearson 1989), but the use of DMS is new. Because of its unique biogeochemical and photochemical properties (cf. Lenschow et al. 1999), DMS was thought to be ideally suited to entrainment estimates in the STBL environment. This helped to motivate the development of a fast DMS sensor (Bandy et al. 2002). The sensor performed well, and DMS behaved as expected. For instance, because of its short lifetime it was not detected above the boundary layer, but was very evident within the STBL, leading to well-defined local jumps across cloud top. What was surprising, and complicated its interpretation, was large horizontal variability $( \pm 25 \%)$ on the mesoscale within the STBL (e.g. Stevens et al. 2003). This variability also projects on the DMS flux plotted in Fig. 8. For this reason, and because $q_{\mathrm{t}}$ and $\mathrm{O}_{3}$ were relatively well behaved above the STBL during RF01, the absolute accuracy of DMS-derived estimates of entrainment was not appreciably better than other estimates during RF01. Nonetheless it does provide an independent estimate which in itself helps reduce the uncertainty.

Fluxes of $q_{\mathrm{t}}$, DMS and $\mathrm{O}_{3}$ are plotted in Fig. 8, and the values of $E$ they imply are tabulated, along with previous budget estimates of $q_{\mathrm{t}}$ and $s_{1}$ in Table $2^{*}$. For these estimates we used fast data collected in all Lagrangian regions; efforts to sort the flux data by region (as was done for the mean state data) did not lead to better behaved estimates. To estimate $E$ from these fluxes, we estimated the jumps as

$$
\Delta q_{\mathrm{t}}=7.5 \pm 0.5 \mathrm{~g} \mathrm{~kg}^{-1}, \Delta \mathrm{DMS}=-60.2 \pm 4.5 \mathrm{pptv}, \Delta \mathrm{O}_{3}=23 \pm 4.3 \mathrm{ppbv}
$$

(see appendix B for details). For the case of DMS almost all of the contribution to $\sigma_{\triangle \mathrm{DMS}}$ is from variability within the boundary layer, while variability above the STBL

\footnotetext{
* We could have performed budget estimates for $\mathrm{O}_{3}$ and DMS as well; however, unlike $q_{\mathrm{t}}$ and $s_{1}$ their values are not constrained by the variation of cloud base. Thus estimates of time-derivative terms are more difficult, making the budget method even more uncertain.
} 


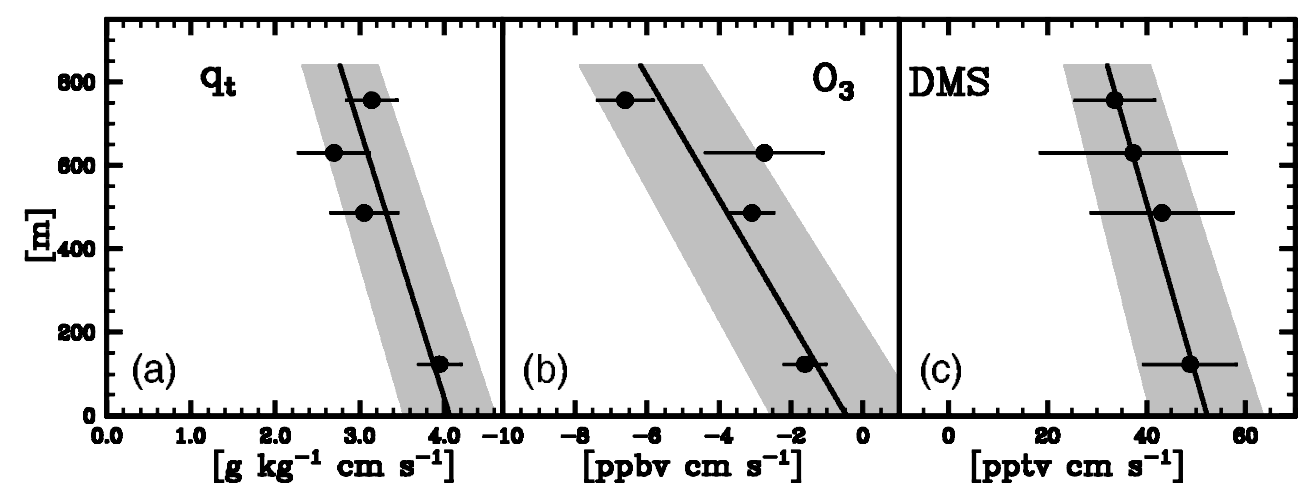

Figure 8. Flux versus height and weighted least-squared linear fit, with uncertainty shaded, for (a) $q_{\mathrm{t}}$, (b) $\mathrm{O}_{3}$, and (c) DMS (see text).

TABLE 2. ENTRAINMENT VELOCITY ESTIMATES

\begin{tabular}{lc}
\hline Method & Estimate $\left(\mathrm{cm} \mathrm{s}^{-1}\right)$ \\
\hline$q_{\mathrm{t}}$ budget & $0.34 \pm 0.11$ \\
$s_{1}$ budget & $0.46 \pm 0.08$ \\
$q_{\mathrm{t}}$ cloud-top flux & $0.37 \pm 0.06$ \\
$\mathrm{O}_{3}$ cloud-top flux & $0.27 \pm 0.09$ \\
DMS cloud-top flux & $0.53 \pm 0.11$ \\
Weighted average & $0.39 \pm 0.04$ \\
\hline
\end{tabular}

See text for explanation of symbols.

explains most of $\sigma_{\mathrm{AO}_{3}}$. The consistency of the various estimates is rather satisfactory, encouraging us to construct a best estimate from the mean of the individual estimates weighted by their uncertainty. Such a procedure yields $E=0.39 \pm 0.04 \mathrm{~cm} \mathrm{~s}^{-1}$. Here it should be emphasized that the uncertainty (order 10\%) includes only the contribution from random sampling errors. Presumably systematic error is responsible for the scatter in estimates of $E$ beyond what one would expect based on the sampling statistics. For sake of argument, if we assume that the systematic error is randomly distributed among the techniques, it can be estimated as the standard deviation of the different estimates of $E$, which is $0.1 \mathrm{~cm} \mathrm{~s}^{-1}$. For this reason, and because values of $E$ greater than 0.5 and less than $0.3 \mathrm{~cm} \mathrm{~s}^{-1}$ become difficult to justify with the existing data, we believe that increasing the uncertainty in the estimate of $E$ to $0.1 \mathrm{~cm} \mathrm{~s}^{-1}$ appropriately accounts for any additional uncertainties associated with unknown systematic errors.

As a further check on the above estimates we can calculate the implied subsidence rate kinematically as $\bar{w}\left(z_{i}\right)=E-\left(\mathrm{d} z_{i} / \mathrm{d} t\right)$. If from Fig. 5 we estimate that $\mathrm{d} z_{i} / \mathrm{d} t \approx 0.1 \pm 0.15 \mathrm{~cm} \mathrm{~s}^{-1}$, this implies that $\bar{w}\left(z_{i}\right)=-0.30 \pm 0.16 \mathrm{~cm} \mathrm{~s}^{-1}$. We can also estimate $\bar{w}\left(z_{i}\right)$ by assuming that the temperature profile in the few hundred metres above the cloud layer is in a radiative subsidence balance, i.e. by assuming that advection by the horizontal winds plays no role in the equation for $S_{1}$ so that $\rho \bar{w}=\left(\partial F_{1 \mathrm{w}} / \partial z\right)\left(\partial s_{1} / \partial z\right)^{-1}$. Such a procedure yields a value of $\bar{w}\left(z_{i}\right)$ of about $-0.35 \pm 0.1 \mathrm{~cm} \mathrm{~s}^{-1}$, which is consistent with our kinematic estimate of $\bar{w}\left(z_{i}\right)$. However, given that our estimate of $\mathrm{d} z_{i} / \mathrm{d} t$ is not strongly constrained by the data, this corroboration is illuminating only insofar as it does not show any gross inconsistencies. 


\section{ENTRAINMENT-RATE PARAMETRIZATIONS (RULES)}

In this section we compare our estimates of $E$ with those predicted from a variety of entrainment rate parametrizations (or rules for short) as reviewed by Stevens (2002). For reference, three of these rules, which we name AL (following Lock 1998), CM (Moeng 2000) and DL (Lilly 2002) are fits one way or another to LES data. What we call the NT rule was proposed by Turton and Nicholls (1987) on the basis of aircraft datahere it is evaluated with two different buoyancy reversal coefficients ( $a_{2}=60$ as first suggested by Turton and Nicholls, or $a_{2}=30$, as is sometimes used in the literature). In addition to evaluating the rules discussed by Stevens (2002) we also consider two additional rules. The first we call AB. It was developed by Lock (1998) to include the case when buoyancy reversal was possible, and hence is particularly relevant here. It was not considered by Stevens (2002) because it does not match the AL rule in the buoyancy neutral limit. The second we call LL (following Lewellen and Lewellen 1999). It was not considered by Stevens et al. (2003), because it depends on a characterization of the radiative-flux divergence across cloud top which has yet to take a testable expression. Here we avoid this shortcoming by simply neglecting this cloud-top term. In this case the parametrization adjusts the rate of entrainment so that the net rate of working is a fixed fraction $(1-\eta)$ of the flux one would find in a non-entraining planetary boundary layer with identical surface and radiative forcings, cf. Stevens (2002). Lewellen and Lewellen have suggested values of $\eta$ between 0.25 and 0.30 . Here we consider the case for $\eta=0.25$.

To apply the rules we use the basic state specified in Table 1 and a specified radiative-flux divergence of $50 \mathrm{Wm}^{-2}$. The surface fluxes in these estimates are calculated using a bulk aerodynamic formula with the estimated SST and a bulk aerodynamic coefficient of 0.0011 . The value of this coefficient was taken to match the surface layer analysis of the previous section, although, because of different treatments of heat and moisture fluxes in the simple algorithm, this approach slightly overestimates (by $\approx 2 \mathrm{Wm}^{-2}$ ) the sensible-heat flux at the expense of the latent-heat flux. In total we consider six cases. Three are considered base cases, one uses our best estimates of the mean state and forcings, and two others are based on a plausible modification to either the mean state, or the forcing. For instance, because of the $\left(z-z_{i}\right)^{3}$ dependence of the $T_{1}$ profile above the boundary layer, it is difficult to determine what effective stability one should use to cap the STBL, hence we consider a case where $\Delta T_{1}$ is larger. In the other case, we use a larger radiative forcing $\left(70 \mathrm{~W} \mathrm{~m}^{-2}\right)$. The motivation for doing so is that it remains unclear how the radiative forcings project on the energetics, and one could argue that it is the cloud-top cooling, rather than the net flux divergence across the layer, which is most directly relevant to entrainment. The second set of three cases was designed to highlight specific sensitivities of various rules. This included a case with a free atmosphere (i.e. $q_{\mathrm{t}}\left(z_{i+}\right)=5 \mathrm{~g} \mathrm{~kg}^{-1}$, so that $\kappa=0$ ), no radiative forcing (i.e. $\Delta F=0$ ), and a neutrally stratified air-sea interface (i.e. SST $=290.4 \mathrm{~K}$ ). Hence the first case illustrates the extent to which rules are sensitive to CTEI. Changing the surface temperature (which reduces sensible-heat flux from 19 to $0 \mathrm{~W} \mathrm{~m}^{-2}$ and latent-heat flux from 113 to $73 \mathrm{~W} \mathrm{~m}^{-2}$ ) or the radiative forcings exposes the sensitivities of the rules to different forcings. Results are tabulated in Table 3.

Of the varied rules, AL and NT (with $a_{2}=60$ ) yield values of $E$ furthest from the observational estimates. By using a smaller value of $a_{2}$ the NT rule becomes more plausible. Including buoyancy reversal in the AL rule (i.e. the AB rule) leads to an overestimate of entrainment; a better effort to match the rules at the buoyancy neutral limit might lead to more plausible results. The DL rule behaves similarly to the NT 
TABLE 3. ENTRAINMENT VELOCITY ESTIMATES $\left(\mathrm{cm} \mathrm{s}^{-1}\right)$ FROM DIFFERENT ENTRAINMENT RULES

\begin{tabular}{lccccccc}
\hline & \multicolumn{3}{c}{ Base cases } & & 3 & Test cases \\
\cline { 2 - 3 } \cline { 7 - 8 } Model & $E$ & $E_{\triangle T_{1}=11}$ & $E_{\triangle F=70}$ & & $E_{\triangle F=0}$ & $E_{q_{t+}=5.0}$ & $E_{\mathrm{SST}=290.4}$ \\
\hline AL & 0.23 & 0.20 & 0.30 & & 0.08 & 0.21 & 0.16 \\
AB & 0.54 & 0.47 & 0.70 & & 0.11 & 0.44 & 0.47 \\
CM & 0.45 & 0.41 & 0.61 & & 0.03 & 0.45 & 0.41 \\
DL & 0.56 & 0.46 & 0.71 & & 0.18 & 0.40 & 0.43 \\
NT $\left(a_{2}=60\right)$ & 0.81 & 0.65 & 1.00 & & 0.36 & 0.59 & 0.54 \\
NT $\left(a_{2}=30\right)$ & 0.57 & 0.46 & 0.70 & & 0.25 & 0.43 & 0.38 \\
LL $(\eta=0.25)$ & 0.46 & 0.37 & 0.57 & & 0.20 & 0.28 & 0.31 \\
\hline
\end{tabular}

See text for explanation.

rule with $a_{2}=30$. Because both explicitly factor in buoyancy reversal they are rather sensitive (relative to the other rules) to the implied value of $\kappa$, as either increasing $\Delta s_{1}$ by $10 \%$ or decreasing the magnitude of $\Delta q_{\mathrm{t}}$ leads to marked changes in the entrainment rate. Although as currently formulated they seem to overestimate entrainment, to the extent that our analysis overestimates $\kappa$, their predicted values of $E$ become increasingly plausible. Both the LL and the CM rule are quite close to the consensus estimate of $E$, although the CM rule predicts a seemingly unreasonable value of $E$ (given the observed surface moisture, and hence implied in cloud buoyancy fluxes) for the hypothetical case of $\triangle F=0$. In many respects the LL rule exhibits sensitivities similar to those of the NT and DL rules; however, it has the advantage of having only one free parameter and being conceptually simpler. This analysis suggests that, because of their varied sensitivities, there is hope for further narrowing the range of plausible rules by comparing their predicted entrainment rates to observations from DYCOMS-II flights for which the radiative forcing was less dominant, or for which $\kappa$ took smaller values.

\section{LARGE-EDDY SIMULATION}

In addition to evaluating entrainment rules, many of which have been calibrated on the basis of LES, it is interesting to also test LES directly. Towards this end LES was performed using the NCAR*-LES (as described by Moeng (2000)) based on an initial state taken directly from the above analysis. Because the LES code of Moeng uses only approximate thermodynamic relations, $q_{\mathrm{t}}$ and $T_{1}$ were adjusted from the values specified in Table 1 so as to preserve the depth of the cloud layer. Specifically, the initial cloud top is set to $z_{i}(t=0)=817 \mathrm{~m}$, slightly lower than the observed height. Below $z_{i 0}$, $q_{\mathrm{t}}$ is set to $8.75 \mathrm{~g} \mathrm{~kg}^{-1}$ and $T_{1}$ to $288.7 \mathrm{~K}$. Above $z_{i 0}, q_{\mathrm{t}}$ is set to $1.5 \mathrm{~g} \mathrm{~kg}^{-1}$ and $T_{1}$ to $296.7+\left(z-z_{i 0}\right)^{(1 / 3)} \mathrm{K}$. This set-up gives room for the LES code to spin up from a nonturbulent state to a fully turbulent state that starts with reasonable cloud base, cloud top, and inversion strength. Because the LES code is based on the Boussinesq approximation, with a constant basic-state density, $\rho=1 \mathrm{~g} \mathrm{~kg}^{-1}$, boundary and radiative fluxes also had to be appropriately adjusted (i.e. by specifying them in terms of kinematic, rather than energetic, values). To mimic the surface forcings estimated from the observations, this resulted in specifying $\overline{w^{\prime} T^{\prime}}=0.015 \mathrm{~K} \mathrm{~m} \mathrm{~s}^{-1}$ and $\overline{w^{\prime} q_{\mathrm{t}}^{\prime}}=0.04 \mathrm{~g} \mathrm{~kg}^{-1} \mathrm{~m} \mathrm{~s}^{-1}$ at the surface. For the radiative forcing a simple exponential decay parametrization was used, i.e.

$$
F_{\mathrm{lw}} /\left(c_{p} \rho\right)=F_{0}\left\{1-\exp \left(-\int_{z}^{\infty} k q_{1} \mathrm{~d} z\right)\right\} .
$$

* National Center for Atmospheric Research. 
Here $F_{0}=0.05 \mathrm{~K} \mathrm{~m} \mathrm{~s}^{-1}$ was chosen to reflect the mean flux divergence across the STBL and $k=130 \mathrm{~g} \mathrm{~m}^{-2}$ was chosen in accord with previous experiments. Note that this choice of radiative parametrization presumes that the only relevant component of the radiative forcings is the net flux divergence across the entire boundary layer, and that it can be modelled as if it were only occurring at cloud top. This will remain as an assumption of the present analysis, but should be further investigated. Above the STBL a radiative-flux divergence equal to $\bar{w} \mathrm{~d} s_{1} / \mathrm{d} z$ was specified to maintain the free troposphere at a constant temperature despite a specified constant rate of divergence of $D=4 \times 10^{-6} \mathrm{~s}^{-1}$, which was chosen to yield a subsidence velocity of $\bar{w}(z) \equiv-D z \approx-0.32 \mathrm{~cm} \mathrm{~s}^{-1}$ at cloud top.

The numerical discretization of the model was based on a mesh with 96 points in each horizontal direction and 400 points in the vertical, leading to a horizontal grid spacing of approximately $26 \mathrm{~m}$ and a vertical spacing of $3.75 \mathrm{~m}$. Thus the domain had a horizontal span of $2500 \mathrm{~m}$ and a vertical span of $1500 \mathrm{~m}$. A simulation on a larger horizontal domain was also performed, but no significant sensitivity to domain size was apparent in the statistics we investigated. The model time step is determined dynamically to maintain stability. The simulation was run for approximately four hours of simulated time, with statistics being collected after the first hour.

Overall the simulated and observed cloud evolution were in satisfactory agreement. Cloud base in the LES descended at about a rate of $6 \mathrm{~m} \mathrm{~h}^{-1}$ and cloud top rose at about $2 \mathrm{~m} \mathrm{~h}^{-1}$. Experiments designed to expose sensitivities to slight changes in the initial parameters and forcings (chosen to mimic uncertainty in radiative fluxes and initial state) and numerics (i.e. using a different vertical advection scheme) did not show marked sensitivities; thus the above level of agreement does not reflect a lucky choice of initial conditions and forcing, but seems to be robust.

However, the LES did show a tendency to evolve away from the initially specified jump conditions. Maintaining the correct entrainment rates for the correct inversionlayer structure proved difficult given our overly simplified approach to radiative transfer. For instance, to maintain the correspondence between the simulated flow and the observed flow one would like the temperature structure above the boundary layer to be consistent with that observed. However, the observed value of $T_{1}$ scales with $\left(z-z_{i}\right)^{1 / 3}$ (cf. (8)), thus an extra $8 \mathrm{~m}$ in the initial growth of the boundary layer is sufficient to increase the strength of the temperature jump by $2 \mathrm{~K}$ (approximately $20 \%$ ) and reduce $\kappa$ to 0.35 . To mitigate this problem we initialized the boundary layer with slightly larger initial values of $\kappa$ (weaker temperature jumps). Nonetheless, this difficulty was not eliminated, and there was some sense that the LES attempted to evolve towards a state in which its mixing lines were decidedly more neutral with respect to CTEI than those observed (cf. Fig. 6). To address these shortcomings requires careful experimentation with more realistic representations of radiative transfer (which given the size of the grid becomes very computationally demanding) and longer-time integrations wherein the turbulent evolution of the layer comes into a better balance with the air just above it. Although these types of experiments are beyond the scope of the present, predominantly observational, study it will be the focus of an upcoming study by the Global Energy and Water Experiment Cloud Systems Studies Working Group 1.

In addition to matching the observed evolution of the cloud boundaries to within experimental uncertainty, the simulation plausibly represented at least some aspects of the observed energetics. This is illustrated in Fig. 9 where we show the measured and simulated profiles of vertical velocity variance, $\sigma_{w}^{2} \equiv \overline{w^{\prime} w^{\prime}}$, and the skewness, $S_{w} \equiv$ $\overline{w^{\prime} w^{\prime} w^{\prime}} / \sigma_{w}^{3 / 2}$. Here the measurements consist of in situ and remotely sensed estimates. 


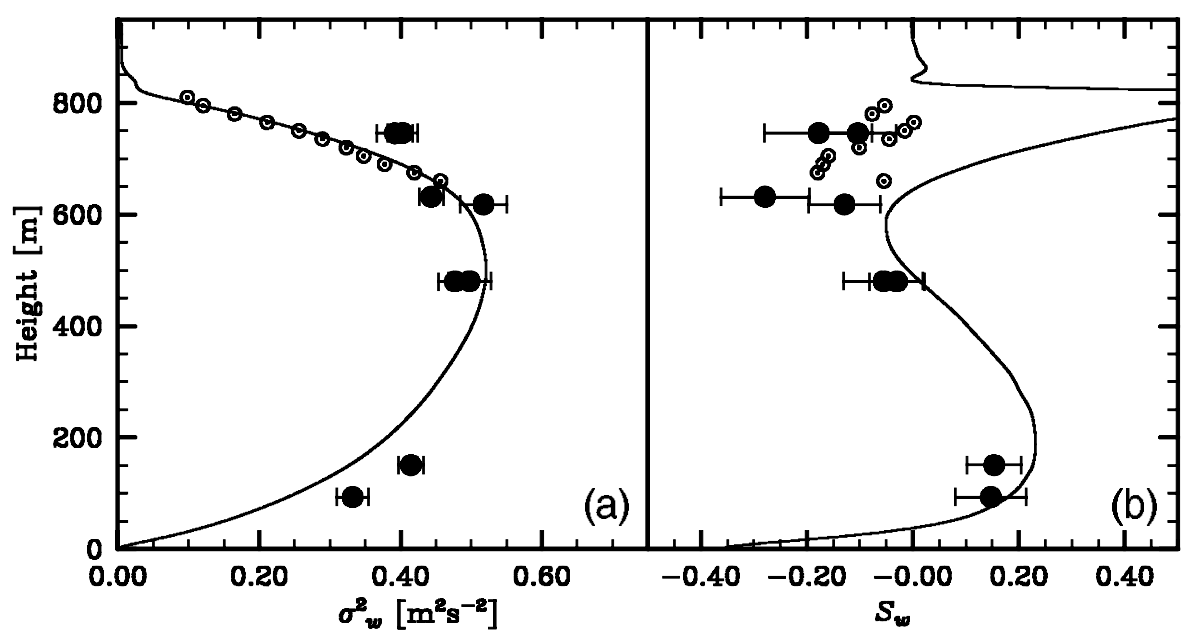

Figure 9. (a) Vertical-velocity variance (resolved plus sub-filter estimate) and (b) skewness. LES results (solid line), radar data (open circles), in situ data (filled circles). The in situ data shows the mean variance and standard deviations about the mean variance for $2.5 \mathrm{~min}(15 \mathrm{~km})$ sub-legs of $30 \mathrm{~min}$ legs.

The remotely sensed estimates are only available in the cloud layer. They correspond to a $700 \mathrm{~s}$ cloud section with very weak echoes (less than $-17 \mathrm{dbZ}$ on average), so that droplet fall velocities should not bias the statistics. Some confirmation of this assumption is provided by an evaluation of the radar derived $\bar{w}$ whose magnitude was less than $0.04 \mathrm{~m} \mathrm{~s}^{-1}$ at the levels for which we have extracted statistics. In general the simulated values of $\sigma_{w}$ agree remarkably with the data.

Note that the disagreement between the radar data and the in situ estimates of $\sigma_{w}$ near cloud top may reflect attenuation of small scales by the radar averaging volume. If this is the case, one could conclude that the LES profile of $\sigma_{w}$ (which does include contributions from the model estimate of subgrid contributions to $\sigma_{w}$ ) varies more sharply with height than do the observed values, but overall it would be difficult to argue that the model is doing a poor job of simulating this quantity. More marked departures between the data and the simulation are evident in the higher-order statistics, as there is a clear indication that the model misrepresents $S_{w}$ in the cloud layer, particularly near cloud top. These failings are reminiscent of past evaluations (e.g. Moeng and Rotunno 1990; Moyer and Young 1991) and might be artifacts of the sub-filter model (note that no sub-filter estimates are available for $S_{w}$ ), in which case they should be less evident as the LES filter length is reduced. This is clearly an area worthy of further investigation.

Despite lingering issues regarding the profiles of turbulent quantities near the flow boundaries, and the ability of the simulation to maintain a layer with the observed values of $\kappa$, the agreement between the LES and the data was better than expected. This might, however, merely be a statement of the extent to which our expectations had been lessened by the apparent discord among previous LESs. Because LES is not expected to (and shows no evidence of) effectively representing the detailed processes occurring at cloud top, these results are encouraging for the method, and to some extent support the idea that the detailed entrainment rate is controlled by macroscopic, or largeeddy processes (e.g. Lewellen and Lewellen 1998). To the extent that these results can be reproduced with flow solvers using different numerics, or more detailed representations of radiative processes, or for other flights during DYCOMS-II, they provide a rational basis for investigating how entrainment depends on a variety of parameters. 


\section{SUMMARY AND CONCLUSIONS}

After corrections for non-Lagrangian effects, data collected during the first research flight of DYCOMS-II show evidence of a stable to deepening cloud layer despite macroscopic conditions thought to favour cloud dissolution through CTEI. Best estimates show cloud base lowering at a rate of several metres per hour; the evolution of cloud top is difficult to discern from its spatial variability except to say that it is not changing markedly. Comparisons of the STBL and free-tropospheric states yield a value of the CTEI stability parameter $\kappa$ of approximately 0.45 - significantly larger than the critical value of 0.23 thought to portend the break-up of the cloud layer. Although past observations have indicated that $\kappa>0.23$ is not a sufficient condition for the dissolution of the cloud layer, recent modelling studies have rehabilitated $\kappa$ as a measure of cloud longevity. Data collected during RF01 should provide meaningful constraints on the theory in this critical region of parameter space.

The observations are also used to make five quasi-independent estimates of entrainment. Each of these estimates is broadly consistent with the others and contributes to a best estimate of the entrainment rate of $E \approx 0.39 \pm 0.1 \mathrm{~cm} \mathrm{~s}^{-1}$. The relatively small uncertainty, which derives from the consistency of the multiple estimates, allows meaningful tests of entrainment rules. Of the five rules tested, two plausibly fit the dataalthough with some adjustment the others can be made to fit the data better. Because these two rules show markedly different sensitivities to environmental parameters such as surface latent-heat fluxes, radiative forcing and values of $\kappa$, the use of data from other flights to further discriminate among these rules may prove useful.

LES was also evaluated against the RF01 data. It was found to well reproduce the macroscopic evolution of the cloud layer, although in so doing it had difficulty in maintaining the observed inversion-layer structure. Because it is uncertain what role detailed radiative processes play in this aspect of the simulation, further work is necessary using LES with more accurate representations of long-wave radiative transfer. Higher-resolution simulations are also necessary to evaluate what appear to be systematic biases in the representation of the structure of the vertical-velocity field near cloud top. Overall, however, the ability of LES to represent the macroscopic evolution of the layer was encouraging, and suggests that the method might be usefully employed to help further discriminate among entrainment rules.

\section{ACKNOWLEDGEMENTS}

The authors would like to acknowledge the many contributions of the engineers, management, pilots, mechanics, and scientists of the Research Aviation Facility and the staff of North Island Naval Air Station who helped facilitate the collection of data during DYCOMS-II. The lead author would also like to acknowledge discussions with Margreet van Zanten, the contributions of Dave Leon in the analysis of the radar data, and the help of Verica Savic-Jovcic in processing the dropsonde data. Extensive discussions with Adrian Lock, as well as suggestions by Chris Bretherton, David Lewellen and Malcolm MacVean, and two anonymous reviewers have led to marked improvements in our analysis. Support by the National Science Foundation, through Grant ATM 0097053 is also gratefully acknowledged.Lastly, Roddy Rogers of National Science Foundation and Dave Carlson of National Center for Atmospheric Research Atmospheric Technology Division are thanked for their support and encouragement. 


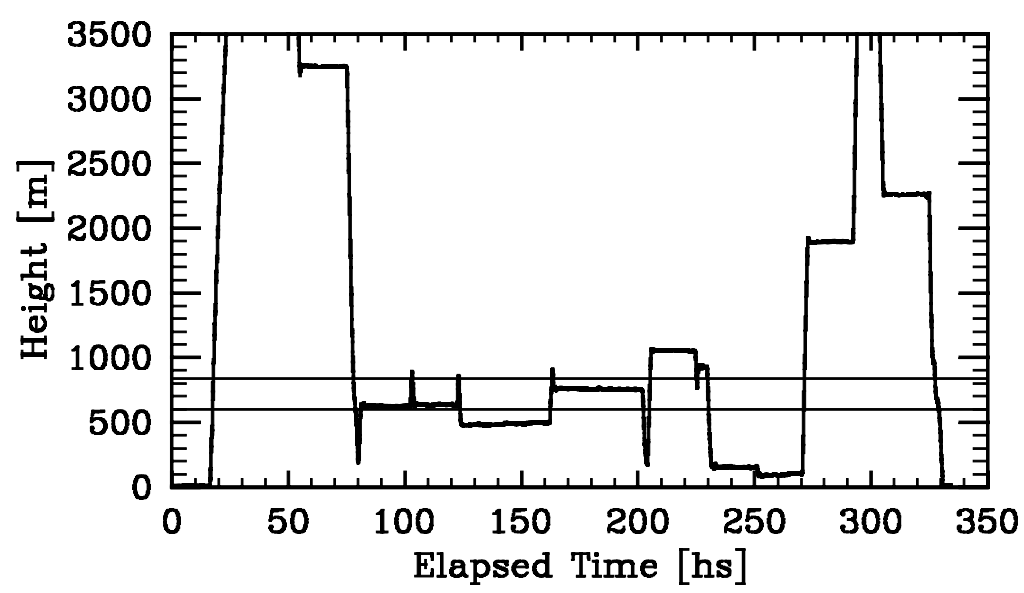

Figure A.1. Altitude versus time for RF01.

APPENDIX A

Data

The distribution of flight time with altitude during RF01 is illustrated in Fig. A.1. With the exception of the leg skimming cloud top (whose latter half incidentally revealed the one instance of a moist layer intersecting cloud top), all level legs were approximately $30 \mathrm{~min}$ circles, flown in alternating clockwise and counter-clockwise directions. For purposes of data analysis the aircraft altitude and roll angle were inspected on all the legs and only those times when the aircraft altitude did not vary significantly (more than $\pm 10 \mathrm{~m}$ from the mean) and the roll angle fluctuated less than a couple of degrees (mean roll angles were about $\pm 2^{\circ}$ for circular legs of radius $30 \mathrm{~km}$ ) were selected for further analysis. This selection results in the segmentation of flight data tabulated in the electronic supplement of Stevens et al. (2003).

During DYCOMS-II, temperature estimates are based on measurements from one of three standard temperature probes. Two of these (ATRR and ATRL) were Rosemount 102E2AL probes mounted on the left and right side of the fuselage. Both have a stated accuracy of $0.5 \mathrm{~K}$. The third probe (ATWH) was a wing-mounted Rosemount 102E deiced probe. It has about twice the error of the 102E2AL. A comparison of the ATRR and ATRL signals indicated a slight drift on two legs towards the beginning of the flight. Further comparisons with ATWH indicated that the source of the drift was the ATRL probe. Thus all the data in this paper is based on the ATRR probe. Because the Research Aviation Facility used ATRL as the base temperature probe, some amount of reanalysis on derived variables was necessary to use ATRR during RF01. On legs where there was no evidence of drift between ATRR and ATRL a comparison of the two showed little indication of wetting effects in the cloud leg.

Humidity data was collected with five probes during DYCOMS-II. Two thermoelectric dew-point hygrometers (General Eastern Instruments 1011B), which were mounted on the top and bottom of the fuselage, provided slow (seconds to tens of seconds) estimates of atmospheric humidity. Fluctuations were measured with cross-flow and stub Lyman- $\alpha$ hygrometers. Generally the cross-flow instrument is thought to be less susceptible to wetting. In addition, a laser hygrometer (or tuneable diode laser (TDL)) 
was flown. In principle the TDL can yield absolute high-rate measurements of humidity, but the data are not yet available. Inspection of the Lyman- $\alpha$ outputs indicated superior frequency response for the cross-flow instrument (MRLA1) and thus it was used in analyses which required fast hygrometer data. When slow data were necessary (i.e. for estimating leg means) the dew-point measurements from the bottom hygrometer were used, because when compared to the measured temperature in cloud legs this instrument performed better. A comparison of all the humidity probes with the saturation humidity as derived from temperature measurements in cloud indicated considerable scatter. Because of the close correspondence between temperature probes (particularly at high frequencies) this scatter was attributed to water effects on the humidity sensors. Hence for mean state estimates the humidity along in-cloud legs was derived by assuming saturation at the measured temperature.

In our analysis all the liquid-water data were taken from the PVM-100 probe. In general its values compared favourably with measurements made with the PMS/ CSIRO hot-wire probes (i.e. the King Probe) mounted on the wings.

To improve the accuracy of the dew-point hygrometers the difference between saturation specific humidity and the specific humidity as measured by the probes was plotted as a function of measured cloud water during cloud legs. This analysis indicated an offset of about $0.25 \mathrm{~g} \mathrm{~kg}^{-1}$ for the dew-point hygrometer versus $q_{\mathrm{s}}$ comparison and an offset of about $0.30 \mathrm{~g} \mathrm{~kg}^{-1}$ when the comparison was made with the Lyman- $\alpha$. These offsets are within the stated accuracies of the instruments. In principle the offset could be attributed to either the temperature or the humidity measurements (i.e. leading to colder and drier estimates of the STBL state), but because of the seemingly poorer performance of the humidity instruments we corrected these for the presumed bias. These corrections, based only on in-cloud data, led to better global agreement between cloud base (as measured from lidar (Graham Feingold, personal communication 2002) and from vertical soundings) and LCL as calculated along all boundary-layer legs.

Downward and upward long-wave $(3.5-50 \mu \mathrm{m})$ radiative fluxes were measured with upward and downward looking Eppley Pyrgeometers. These instruments require calibration and have no stated absolute accuracy. In our comparisons with calculated radiative fluxes, 'eye-estimated' offsets of 17 and $14 \mathrm{~W} \mathrm{~m}^{-2}$ were added to the downward and upward measured fluxes, respectively, to yield better agreement with calculated fluxes based on the mean state. Past experience (Krista Laursen, personal communication 2002) indicates that such adjustments are reasonable. Moreover, since all of the analysis in this paper depends on differences in the net flux with height, the addition of a constant offset to the flux has no impact.

Surface temperatures were estimated using two Heimann Infrared (KT19.85) Radiometric Bolometers. Generally they agreed to much better than the stated accuracy of the instrument $(0.5 \mathrm{~K})$, although they indicated temperatures consistently $0.5 \mathrm{~K}$ warmer than satellite-derived estimates.

Lidar-derived cloud-top heights were determined by the maximum backscatter in the range interval where the cloud top is expected. The intent of using a range interval was to eliminate the near field return which could give false cloud-top measurements on flight legs very near cloud top. Lidar range was converted into cloud-top height using the aircraft altitude and attitude, and correcting for additional range dilation associated with aircraft roll angles. Offsets in range based aircraft altitude and aircraft altitude were also applied when surface returns were available. Overall the differences between infrared and green wavelength cloud-top heights were not found to be significant, and the accuracy of the lidar-derived cloud-top heights is estimated as \pm 1 range bin, equivalently $\pm 3.75 \mathrm{~m}$. 
DMS was measured by an atmospheric pressure ionization mass spectrometer developed at Drexel University (Bandy et al. 2002). Protonation of DMS is achieved by hydronium ions and clusters at near ambient pressures. Sampling of the mass peak at $\mathrm{DMSH}^{+}$and isotopically labelled DMS takes place each at $25 \mathrm{~Hz}$.

Ozone was measured using a reverse chemiluminescence technique built at NCAR's Research Aviation Facility in 2001 and is very similar to that documented in Pearson and Stedman (1980). Continuous in-flight calibration is maintained by running a slower response UV photometric (Thermo Environmental Instruments) analyser in parallel. The minimum detection limit of the fast instrument is estimated to be less than $0.075 \mathrm{ppbv}$ in one second; however, the accuracy, as tied to the slower-response instrument which is in turn calibrated against a transfer standard, is \pm 1 ppbv. The nominal bandwidth of the chemiluminescence instrument is near $10 \mathrm{~Hz}$, limited by the residence time of the air sample within the detection chamber. A more thorough discussion of the instrument performance and the cospectral behaviour of the scalar fluxes may be found in a forthcoming manuscript (Faloona, personal communication).

Turbulent fluxes were calculated using $2.5 \mathrm{~min}(\approx 15 \mathrm{~km})$ sub-segments over which the tracer and the velocity field were demeaned and detrended. The length of the interval was settled upon after a perusal of many scalar/vertical wind-speed cospectra. Nonetheless, it is somewhat arbitrary and does moderately affect the fluxes. However, inspection of the cospectra indicates that it is likely that there is no bias in fluxes due to the filter cut-off (i.e. sometimes the larger scales contribute positively and sometimes negatively), so the error is somewhat accounted for in the scatter of the fluxes.

\section{APPENDIX B}

\section{Error estimates}

Errors were estimated using standard methods (e.g. Bevington 1969; Taylor 1982). For instance, the uncertainty in the estimate of an expression $f\left(x_{1}, x_{2}, \ldots x_{n}\right)$ is denoted $\sigma_{f}$ and is estimated as

$$
\sigma_{f}^{2}=\sum_{i=1}^{n}\left(\frac{\partial f}{\partial x_{i}} \sigma_{x_{i}}\right)^{2}
$$

which assumes that the uncertainties in the $x_{i}$ s are independent. This form of calculation was used to propagate errors in estimates such as (10) and (11), as well as estimates of $E$ using the ratio method, or in estimates of the surface fluxes derived from the bulk-flux algorithm.

For the most part the individual component errors which make up the total error in the final entrainment estimate were assumed to be independent. In the final calculation of entrainment based on the jump and the flux at the inversion (see(5)), it is possible to make other arguments. Since we have reason to believe that the thermodynamic environment and the entrainment velocity are relatively uniform across the horizontal scales of the experiment, it follows that the magnitude of the scalar flux at the cloud top is correlated with its jump, in which case

$$
\left(\frac{\sigma_{E}}{E}\right)^{2}=\left(\frac{\sigma_{\Delta}}{\Delta}\right)^{2}+\left(\frac{\sigma_{\psi}}{\psi}\right)^{2}-2 r\left(\frac{\sigma_{\Delta}}{\Delta}\right)\left(\frac{\sigma_{\psi}}{\psi}\right),
$$

where $r$ is the coefficient of linear correlation between $\Delta$ and $\psi$. For DMS the jump can be expected to equal the mean concentration in the boundary layer, in which case one 
can assume $r=-1$. Because this strong relationship between the flux and the jump is only expected to hold for DMS, the $r$ term above (with $r=-1$ ) was only applied for the estimate of the uncertainty analysis of DMS. It resulted in a reduction of our estimated error from $0.15 \mathrm{~cm} \mathrm{~s}^{-1}$ (without the covariance term) to the stated value of $0.11 \mathrm{~cm} \mathrm{~s}^{-1}$.

Estimates of the uncertainty of a flux profile were derived by fitting lines of the form*

$$
\hat{\psi}=\psi_{*}+b\left(z-z_{*}\right),
$$

with $z_{*}=0$ and $z_{*}=z_{i}$ to the $n$ data pairs $\left(z_{i}, \psi_{i}\right)$. For a given $z_{*}$ we estimate the uncertainty in the intercept as

$$
\sigma_{\psi_{*}}^{2}=\frac{\sum_{i=1}^{n} w_{i} z_{i}^{2}}{\sum_{i=1}^{n} w_{i} \sum_{i=1}^{n}\left(w_{i} z_{i}^{2}\right)-\left(\sum_{i=1}^{n} w_{i} z_{i}\right)^{2}}, \quad \text { where } \quad w_{i}=\sigma_{\psi_{i}}^{-2} .
$$

We then bound our estimate of the flux by the rhomboid defined by uncertainty in the surface and cloud-top (e.g. $z_{i}$ ) intercepts. To estimate $\sigma_{\psi_{i}}$, the uncertainty of the flux at some height $z_{i}$, in the above expression we calculate an intrinsic uncertainty, $\left.\sigma_{\psi_{i}}\right|_{\mathrm{t}}$, due to turbulent fluctuations using the integral scale of the quantity whose flux we are interested in (e.g. following Mann and Lenschow 1994) and a mesoscale uncertainty associated with measuring fluxes at different times, or possibly in different regions. This mesoscale uncertainty is estimated from our fit as

$$
\left(\left.\sigma_{\psi}\right|_{m}\right)^{2}=\frac{1}{n-2} \sum_{i=1}^{n}\left(\hat{\psi}-\psi_{i}\right)^{2}
$$

Assuming that the turbulence and mesoscale contributions to the error are independent leads us to conservatively estimate $\sigma_{\psi}^{2}=\left(\left.\sigma_{\psi}\right|_{m}\right)^{2}+\left(\left.\sigma_{\psi_{i}}\right|_{\mathrm{t}}\right)^{2}$

The jumps in scalar quantities appear repeatedly in our equations. To estimate the jumps in $\mathrm{O}_{3}, q_{\mathrm{t}}$ and $s_{1}$ we use a mixing diagram, and errors in the jumps are estimated using a combination of the mean values in the STBL and in the above-cloud legs. One advantage of DMS in this regard is that, because it is zero above the STBL, the uncertainty in its jump is just the uncertainty in its mean STBL value.

\section{REFERENCES}

Bandy, A. R., Thornton D. C., Tu, F. H., Blomquist, B. W., Nadler, W., Mitchell, G. M. and Lenschow, D. H.

Bevington, P. R.

Bretherton, C. S., MacVean, M., Bechtold, P., Chlond, A.,

Cotton, W., Cuxart, J.,

Cuijpers, H.,

Khairoutdinov, M.

Kosovic, B., Lewellen, D.,

Moeng, C.-H., Siebesma, P.,

Stevens, B., Stevens, D.,

Sykes I. and Wyant, M.

Deardorff, J. W.
2002 Determination of the vertical flux of dimethyl sulfide by eddy correlation and atmospheric pressure ionization mass spectrometry (APIMS). J. Geophys. Res., 107, doi:10.1029/2002JD002472

1969 Data reduction and error analysis for the physical sciences. McGraw-Hill, New York

1999 An intercomparison of radiatively driven entrainment and turbulence in a smoke cloud, as simulated by different numerical models. Q. J. R. Meteorol. Soc., 125, 391-423

1980 Cloud-top entrainment instability. J. Atmos. Sci., 37, 131-147

* Strictly speaking this was only done for scalars for which $F$, the non-turbulent flux, vanished, and for which $S$ was either negligible or constant throughout the STBL. Because $s_{1}$ does not satisfy this requirement we actually fit a line to the sum of $\psi_{s l}$ and $F_{1 \mathrm{~W}}$. 
Fairall, C. W., Bradley, E. F., Rogers, D. P., Edson, J. B. and Young, G. S.

$\mathrm{Fu}, \mathrm{Q}$. and Liou, K.-N.

Gerber, H., Malinowski, S. P., Brenguier, J.-P. and Burnet, F.

Kawa, S. R. and Pearson, R., Jr.

Kuo, H.-C. and Schubert, W.

Lenschow, D. H., Krummel, P. B. and Siems, S. T.

Lewellen, D. and Lewellen, W.

Lilly, D. K.

Lock, A. P.

Lock, A. P. and MacVean, M. K.

Mann, J. and Lenschow, D. H.

Moeng, C.-H.

Moeng, C.-H. and R. Rotunno

Moeng, C.-H., Cotton, W. R., Stevens, B., Bretherton, C., Rand, H. A., Chlond, A.,

Khairoutdinov, M.,

Krueger, S., Lewellen, W. S., MacVean, M. K.,

Pasquier, J. R. M.,

Siebesma, A. P. and

Sykes, R. I.

Moeng, C.-H., Sullivan, P. P. and Stevens, B.

Moyer, K. A. and Young, G. S.

Pearson, R., Jr and Stedman, D. H.

Phillips, O. M

Randall, D. A.

Russell, L. M., Lenschow, D. H., Laursen, K. K.,

Krummel, P. B., Siems, S. T., Bandy, A., Thornton, D. and Bates, T. S.

Schubert, W. H., Wakefield, J. S., Steiner, E. J. and Cox, S. K.

Stevens, B.
1989

1996

1993

2002

1988

1999

1998

1968

2002

1998

1999

1994

2000

1990

1996

1999

1991

1980

1966

1980

1998

1979

2002
Bulk parametrization of air-sea fluxes for tropical ocean global atmosphere coupled ocean-atmosphere response experiment. J. Geophys. Res., 101, 3747-3764

Parametrization of the radiative properties of cirrus clouds. J. Atmos. Sci., 50, 2008-2025

'On the entrainment process in stratocumulus clouds'. In Preprints of 11th conference on cloud physics, 3-7 June 2002, Ogden, UT, USA. American Meteorological Society, 45 Beacon Street, Boston MA02108-3693, USA (Available on CD-ROM, JP7.6)

An observational study of stratocumulus entrainment and thermodynamics. J. Atmos. Sci. . 46, 2649-2661

Stability of cloud-topped boundary layers. Q. J. R. Meteorol. Soc., 114, 887-916

Measuring entrainment, divergence, and vorticity on the mesoscale from aircraft. J. Atmos. Oceanic Technol., 14, 13841400 .

Large-eddy boundary layer entrainment. J. Atmos. Sci., 55, 2645 2665

Models of cloud-topped mixed layers under a strong inversion. Q. J. R. Meteorol. Soc., 94, 292-309

Entrainment into cloud-topped mixed layers: A new closure. J. Atmos. Sci., 59, 3353-3361

The parametrization of entrainment in cloudy boundary layers. Q. J. R. Meteorol. Soc., 124, 2729-2753

The generation of turbulence and entrainment by buoyancy reversal. Q. J. R. Meteorol. Soc., 125, 1017-1038

Errors in airborne flux measurements. J. Geophys. Res., 99, 14519-14526

Entrainment rate, cloud fraction and liquid water path of PBL stratocumulus clouds. J. Atmos. Sci., 57, 3627-3643

Vertical-velocity skewness in the buoyancy-driven boundary layer. J. Atmos. Sci., 47, 1149-1162

Simulation of a stratocumulus-topped planetary boundary layer: Intercomparison among different numerical codes. Bull. Am. Meteorol. Soc., 77, 261-278

Including radiative effects in an entrainment-rate formula for buoyancy driven PBLs. J. Atmos. Sci., 56, 1031-1049

Observations of vertical velocity skewness within the marine stratocumulus-topped boundary layer. J. Atmos. Sci., 48 , $403-410$

Instrumentation for fast response ozone measurements from aircraft, Atmos. Technol., 12, 51-55

The dynamics of the upper ocean. Cambridge University Press

Conditional instability of the first kind upside-down. J. Atmos. Sci., 37, 125-130

Bidirectional mixing in an ACE-1 marine PBL overlain by a second turbulent layer. J. Geophys. Res., 103, 16411-16432

Marine stratocumulus convection. Part II: Horizontally inhomogeneous solutions. J. Atmos. Sci., 36, 1308-1324

Entrainment in stratocumulus-topped mixed layers $Q . J . R$. Meteorol. Soc., 128, 2663-2690 
Stevens, B., Lenschow, D. H., Vali, G., Gerber, H.,

Bandy, A., Blomquist, B., Brenguier, J.-L.,

Bretherton, C. S., Burnet, F., Campos, T., Chai, S.,

Faloona, I., Friesen, D.,

Haimov, S., Laursen, K., Lilly, D. K., Loehrer, S. M., Malinowski, S. P., Morley, B., Petters, M. D., Rogers, D. C.,

Russell, L., Savic-Jovcic, V.,

Snider, J. R., Straub, D.,

Szumowski, M. J., Takagi, H.,

Thornton, D. C., Tschudi, M.,

Twohy, C., Wetzel, M., van Zanten, M. C.

Taylor, J. R.

Turton, J. D. and Nicholls, S.

Vali, G., Kelly, R. D., French, J., Haimov, S., Leon, D., McIntosh, R. E. and Pazmany, A.
2003 Dynamics and chemistry of marine stratocumulus-DYCOMS-II. Bull. Am. Meteorol. Soc., 83, 579-593

1982 An introduction to error analysis: The study of uncertainties in physical measurements. University Science Books, Mill Valley CA

1987 A study of the diurnal variation of stratocumulus using a multiple mixed-layer model. Q. J. R. Meteorol. Soc., 113, 969-1009

1998 Finescale structure and microphysics of coastal stratus. J. Atmos. Sci., 55, 3540-3564 